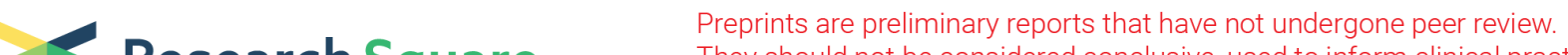 Research Square They should not be considered conclusive, used to inform clinical practice, or referenced by the media as validated information.
}

\section{Chalcone Derivative B8HA as A Novel Histone Deacetylase and Tubulin Dual Inhibitors, Inhibits Triple-Negative Breast Cancer Cells Proliferation}

kangkang li

Qingdao University

qiuling zheng

Qindao University Medical College Affiliated Yantai Yuhuangding Hospital

shulei qi

Qingdao University

yi xie

Qingdao University

xuehong chen ( $\nabla$ chenxuehong@qdu.edu.cn )

Qingdao University https://orcid.org/0000-0001-8214-5569

\section{Research Article}

Keywords: Histone deacetylase, Tubulin, Dual-target inhibitor, Triple-negative breast cancer (TNBC), Antiangiogenesis

Posted Date: February 4th, 2022

DOI: https://doi.org/10.21203/rs.3.rs-1308134/v1

License: (c) (1) This work is licensed under a Creative Commons Attribution 4.0 International License. Read Full License 


\section{Abstract}

Designing and synthesizing dual- and multi-target drugs have raised considerable interests due to their advantages in improving potencies as antitumor agents. In previous studies, our group designed and synthesized a series of novel chalcone based tubulin and histone deacetylase (HDAC) dual-targeting inhibitors. Among them, compound B8HA exhibited promising potency for the treatment of triple-negative breast cancer. In this work, we highlighted its biological evaluations in MDA-MB-231 and 4T1 cells, including anti-proliferative effects, cell cycle arresting effects, anti-metastatic and anti-angiogenesis effects. In vivo results further demonstrated that B8HA significantly inhibited the 4T1 breast tumor growth and destroyed tumor blood vessel as compared to its counterparts. The results indicated that compound B8HA could be a potent inhibitor of both HDAC and tubulin, leading to excellent in vitro and in vivo antiproliferative activities, and is a promising therapeutic agent for triple-negative breast cancer.

\section{Introduction}

Breast cancer (BC) is the leading cause of cancer mortality in females. Triple-negative breast cancer (TNBC) approximately accounts for $15-20 \%$ in all BC and is defined by the lack of progesterone receptor (PR), estrogen receptor (ER) and human epidermal growth receptor 2 (HER2) expression ${ }^{1}$. Due to its high proliferative property, relatively poor prognosis, higher incidence of distant metastasis and the lack of available targeted therapies ${ }^{2}$, effective treatments for TNBC remains to be explored ${ }^{3}$. Nowadays, the conventional chemotherapeutic agents are still the mainstay of the therapeutic protocols for TNBC patients. Although the general chemotherapy treatments based on anthracyclines, anti-metabolites and taxanes could improve the outcomes in patients with TNBC, the inevitable prevalence of drug resistance and unbearable side effects generally lead to incomplete and temporary antitumor effects of these agents, highlighting the need for safer and more effective drugs ${ }^{4}$. Given the fact that epigenetic processes control both the initiation and progression of $\mathrm{TNBC}^{5}$, there is an increasing interest in the mechanisms, molecules and signaling pathways that participate in the epigenetic modulation of genes expressed in the carcinogenesis of TNBC, which also highlight the potential of using histone deacetylase inhibitors (HDACi) for treatment of $\mathrm{TNBC}^{6}$.

HDACs, frequently overexpressed in many malignancies including $\mathrm{TNBC}^{7}$, play essential roles in both transcription regulations and protein modifications by participating in the deacetylation process of the lysine residues that are present on histone tails. Therefore, FDA has approved four HDACis for tumor chemotherapies: Vorinostat (SAHA), Romidepsin (FK-228), Belinostat (PXD-101), and Panobinostat (LBH5890). Furthermore, more HDACis are in clinical trial phase $1 \mathrm{II}^{8}$. However, it is generally accepted now, that tumors are multifactorial, resulting from genetic and/or epigenetic alterations and subsequent dysregulation of various pathways through diverse molecular mechanisms. As a results, single-targeted anti-tumor drugs are unlikely to be sufficiently effective against tumor progression. Meanwhile, combined therapies simultaneously using two or more drugs on different targets are often negated by adverse drugdrug interactions, different solubility, unpredictable pharmacokinetic and safety profiles ${ }^{9}$. Thus, there has 
been an increasing inclination towards developing multitarget inhibitors to address these limitations ${ }^{10}$. HDACis have strong versatility to combine their pharmacophoric structural features to hybridize with different pharmacophore entities in a single drug molecule ${ }^{11}$. At the same time, a recent report of successful synergism of microtubule-destabilizing agent vincristine and HDACi SAHA in leukemia in vitro and in vivo established the approach for development of hybrid anticancer molecules with dual tubulin polymerization and HDAC inhibitory activities ${ }^{12}$. Several attempts are therefore being made to improve the anticancer efficacy via developing a hybrid antitumor agent that contains the colchicine tubulin inhibitor nucleus, such as the first SAHA/colchicine hybrid developed by Zhang X. et al, which showed promising antiproliferative potency against five cancer cell line (A431, A549, HCT-116, MCF-7 and PC-3) ${ }^{13}$. Subsequently, they further explored this kind of tubulin-HDAC dual inhibitors and synthesized a new series of colchicine derivatives based on previous studies, exhibiting similar anti-tubulin activities with colchicine and superior cytotoxicities to Mocetinostat in vitro ${ }^{14}$. Lamaa et al. designed and synthesized another series of hybrids with dual HDAC/tubulin inhibitions through merging of the pharmacophoric structural features of CA-4 and of PXD-101. These products displayed potent HDAC and tubulin-assembly inhibition activities and exhibited remarkable antiproliferative activities on A549 cell line ${ }^{15}$. Wang et al. reported a series of novel colchicine binding site-based tubulin/HDAC hybrid inhibitors ${ }^{16}$. Among these compounds, B8HA (Fig. 1) was identified as one of the most promising agents for cancer treatment. The results of antiproliferative assays on several human tumor cell lines revealed that compound B8HA displayed the strongest anti-proliferative activities against MDA-MB-231 and 4T1 cell lines.

In this work, the antiproliferative effects of B8HA on breast cancer cells were further investigated. Classical HDAC inhibitor SAHA and tubulin inhibitor CA-4 served as the positive control compounds to evaluate the anti-proliferative activities (including cell cycle arresting and apoptotic effects) and antimetastasis activities of B8HA in vitro and in vivo. In addition, the potencies of B8HA as inhibitors of HDAC and tubulin polymerase were also evaluated. Finally, anti-tumor and antiangiogenesis effects were explored with immunohistochemistry $(\mathrm{IHC})$ and TUNEL assay in 4T1 mice model. The results suggested that B8HA is a promising new potential anticancer agent for TNBC.

\section{Materials And Methods}

\subsection{Chemicals}

Vorinostat (CAS:149647-78-9) and Combretastatin A4 (CAS: 117048-59-6) were purchased from Beyotime (Shanghai, China). B8HA was synthesized according to a previous report ${ }^{16}$ and dissolved in dimethyl sulfoxide (DMSO) to a stock concentration of $100 \mathrm{mM}$ and stored at $-20{ }^{\circ} \mathrm{C}$. The final concentration of DMSO in all experiments did not exceed $0.1 \%$ and the final B8HA solutions were all diluted in the fresh culture medium or saline.

\subsection{Mice and Cell Line}


Balb/c mice (4-6 weeks old, 18-20g, female) were purchased from Pengyue (Jinnan, Shandong, China) and kept under specific pathogen-free conditions at $23 \pm 2^{\circ} \mathrm{C}$ with water and food given ad libitum. Experiments and care/welfare were in agreement with a protocol approved by the Qingdao University Animal Studies Committee. MDA-MB-231, 4T1 and HUVEC cell lines were purchased from ATCC. MDAMB-231 and 4T1 were cultured in RPM1640 (Cienry, Zhejiang, China) supplemented with 10\% FBS (Omni, US) and $1 \%$ penicillin/streptomycin (Cienry, Zhejiang, China) at $37^{\circ} \mathrm{C}$ in a humidified atmosphere with $5 \%$ $\mathrm{CO}_{2}$. HUVEC were maintained in HUVEC special culture medium (Procell, Wuhan, China) supplemented with $10 \% \mathrm{FBS}$ and $1 \%$ penicillin/streptomycin at $37^{\circ} \mathrm{C}$ in a humidified atmosphere with $5 \% \mathrm{CO}_{2}$.

\subsection{In Vitro Cell Cytotoxicity}

In vitro cytotoxicities of the tested compounds were investigated using the MTT assay. $5 \times 10^{3}$ breast cancer cells were seeded in flat-bottomed 96 -well plates in complete RPM1640 $(0.2 \mathrm{ml} /$ well $)$ at $37^{\circ} \mathrm{C}$ in a humidified $5 \% \mathrm{CO}_{2}$ incubator for 24 hours. After medium removal, $100 \mu \mathrm{L}$ of serum-free culture medium containing the test compounds at specific concentrations was added to each well and incubated at $37^{\circ} \mathrm{C}$ for another 48 hours. MTT solution $(10 \mu \mathrm{g} / \mathrm{mL})$ was then added and cells were incubated for another 4 hours followed by the addition of DMSO to dissolve the formazan crystals. The absorbance at 490nm was recorded with a spectrophotometric plate reader (SynergyMx, BioTek, USA). The cell viability was calculated using the following formula and $\mathrm{IC}_{50}$ values were calculated through Graph Prism software (San Diego, CA, USA).

$$
\text { CellViability }(\backslash \%)=\frac{A_{\text {drug }}-A_{\text {blank }}}{A_{\text {control }}-A_{\text {blank }}} \times 100 \backslash \%
$$

$A_{\text {Drug }}$ and $A_{\text {Control }}$ denotes the absorbance in the presence and absence of different drugs, respectively; meanwhile, $A_{B l a n k}$ denotes the absorbance of the blank culture medium.

\subsection{Apoptotic Assays by Flow Cytometry}

Apoptosis were investigated using Annexin V-FITC-PI and PI staining followed by flow cytometry, respectively. Briefly, $3 \cdot 10^{5}$ MDA-MB-231 cells were seeded in 6-well plates 24 hours prior to treatment with inhibitors or with relevant controls in serum free culture medium. After treatment for 24 hours as described above, both adherent and suspension cells were harvested, stained with PI and Annexin V-FITC Apoptosis Detection Kit (BD, US) according to the manufacturer's instructions, and analyzed with a CytoFlex S flow cytometer (Beckman, France).

\subsection{Cell Cycle Analysis}

MDA-MB-231 and 4T1 were used for cell cycle analysis. Cells treated with inhibitors for $24 \mathrm{~h}$ were trypsinized, harvested and fixed in $70 \%$ ice cold ethanol at $4^{\circ} \mathrm{C}$ for $12 \mathrm{~h}$. Next, these cells were washed with PBS and stained with PI at room temperature for $0.5 \mathrm{~h}$. The cells cycle distribution was determined and analyzed with a CytoFlex S flow cytometer (Beckman, France).

\subsection{Wound-healing Assay}


MDA-MB-231 and 4T1 were seeded in 6-well plates, and cultured overnight to reach a monolayer of confluence. The cells were wounded by scratching with pipet tips and washed twice by PBS to remove the non-adherent cells. Fresh RPM1640 medium containing specific concentrations of inhibitors was added, and the cells were incubated for 24 hours. Images were taken with an inverted microscope Eclipse Ts2 (Nikon, Japan).

\subsection{Transwell Assay}

Transwell inserts (Corning, US) were coated overnight at $4^{\circ} \mathrm{C}$ with $100 \mu \mathrm{l}$ Matrigel solution (BD, US) (0.2$0.3 \mathrm{mg} / \mathrm{mL}$, diluted with serum-free medium). $200 \mu \mathrm{H}$ HUVEC cell suspensions ( $5 \times 10^{4}$ cells) containing B8HA $(2 \mu \mathrm{M}$ or $4 \mu \mathrm{M})$ were added into the transwell inserts and placed in 24-well plates containing $0.6 \mathrm{ml}$ medium with $15 \%$ serum. Following 24-hours incubation, the upper surfaces of the inserts were washed with PBS to remove non-migrated cells. The inserts were penetrated with ethyl alcohol for 30 minutes and incubated with $0.1 \%$ crystal violet (Solarbio, Beijing, China) for 20 minutes. Finally, the inserts were observed and photographed under inverted microscope Eclipse Ts2 (Nikon, Japan).

\subsection{Antivascular Assay}

The ability of compound B8HA in a tube formation assay were evaluated. In briefly, Matrigel matrix (BD, US) was thawed at $4^{\circ} \mathrm{C}$ overnight, and HUVEC cells suspended in culture medium were seeded and incubated for 12 hours in 96 -well culture plates at a cell density of $5 \times 10^{3}$ cells/well after polymerization of the Matrigel at $37^{\circ} \mathrm{C}$ for 30 minutes. Then they were treated with specific concentrations of compounds B8HA, SAHA or CA-4 for 9 hours at $37^{\circ} \mathrm{C}$. The morphological changes of the cells and tubes formed were observed and photographed under an inverted microscope Eclipse Ts2 (Nikon, Japan).

The vascular disrupting activity of compound B8HA were also investigated. After polymerization of the Matrigel at $37^{\circ} \mathrm{C}$ for 30 minutes, HUVEC cell suspensions with different inhibitors were seeded in 96-well culture plates at a cell density of $5 \times 10^{3}$ cells/well. The morphological changes of the cells and tubes formed were observed and photographed under an inverted microscope Eclipse Ts2 (Nikon, Japan).

\subsection{Microtubule Imaging Using Immunofluorescence Microscopy}

HUVEC cells $\left(2 \times 10^{5}\right.$ cells/well) were cultured on coverslips in 24-well culture plates for 6 hours. Following treatment with B8HA or positive drugs for 16 hours, the cells were fixed with $4 \%$ paraformaldehyde and penetrated with PBS for three times. The resulting coverslips were permeabilized with $0.1 \%$ Triton-X 100 , and then stained with deep red CytoPainter F-Actin stainingsolution (Abcam, US) and 4',6-diamidino-2phenylindole (DAPI, Beyotime, Shanghai, China). Samples were stored in a $4^{\circ} \mathrm{C}$ refrigerator prior to Leica TCS SP8 fluorescence confocal imaging (Leica, Germany).

\subsection{Western Blotting Analysis}

Cells treated with B8HA or positive drugs for 48 hours were lysed in RIPA buffer (Solarbio, Beijing, China) containing PMSF Solution (Solarbio, Beijing, China). The protein concentrations were quantitated with 
BCA Protein Quantification Kit (Solarbio, Beijing, China). $30 \mu \mathrm{g} /$ sample were subjected to SDS-PAGE, transferred to a PVDF membrane (Merk Millipore, US), blocked with 5\% skim milk for $1 \mathrm{~h}$, and then probed overnight at $4{ }^{\circ} \mathrm{C}$ with primary antibodies (1:1000, Bioss, Beijing, China). After 3 washes with PBST (PBS with $0.1 \%$ Tween-20), the membrane was incubated for $1 \mathrm{~h}$ at room temperature with HRP-linked secondary antibodies (1:1000, Bioss, Beijing, China). Bands were visualized with ECL chemiluminescence detection kit (Vazyme, Nanjing, China). A chemiluminescence imager FUSION Solo S (Vilber, Paris, France) was used for analyzing the bands. Densitometry analysis was performed with Image $\mathrm{J}$ software $(\mathrm{NIH}, \mathrm{US})$.

\subsection{In Vivo Antitumor Efficacy in 4T1 Tumor-bearing Mice}

Female mice (Balb/c, 4-6 weeks old, 18-20 g) were injected with $0.2 \mathrm{ml}$ PBS containing 4T1 $\left(5 \times 10^{6} / \mathrm{ml}\right)$ subcutaneously into the fourth inguinal mammary fat pad. The body weight, tumor diameters and appearance were monitored every two days. Tumor volumes were calculated with the following formula: Volume $=\left(L \times W^{2}\right) / 2(L$ : length, $W$ : width $)$. When the tumor volumes reached $50 \mathrm{~mm}^{3}$, animals were randomly divided into six treatment groups (5 mice per group):

(1) $5 \mathrm{mg} / \mathrm{kg} \mathrm{B8HA}$, (2) $10 \mathrm{mg} / \mathrm{kg}$ B8HA, (3) $15 \mathrm{mg} / \mathrm{kg} \mathrm{B8HA}$, (4) $25 \mathrm{mg} / \mathrm{kg}$ SAHA, (5) $25 \mathrm{mg} / \mathrm{kg} \mathrm{CA}-4$, (6) Saline.

The inhibitors and saline were administrated every 2 days. 11 days after the first drug administration, mice were sacrificed after anesthesia with chloral hydrate, tumor tissues were dissected, harvested and weighted followed by immersion into $4 \%$ paraformaldehyde for further histopathological investigation. The tumor growth inhibition (TGI) was calculated by the following equation:

$$
T G I(\%)=\frac{\left(V_{t} / V_{0}\right)_{\text {testedgroup }}}{\left(V_{t} / V_{0}\right)_{\text {salinegroup }}}
$$

Where $V_{t}$ and $V_{0}$ denote the tumor volume at the beginning and ending.

\subsection{Immunohistochemistry (IHC) and TUNEL Assay}

For histological evaluation, the excised tumor tissues and organs were fixed in $4 \%$ polyoxymethylene, and embedded in paraffin. Continuous sections were deparaffinized in xylene, rehydrated in gradient ethanol, and immersed in deionized water. Antigen retrieval was performed by heating the samples in $0.01 \mathrm{M}$ sodium citrate antigen-repair buffer in microwave oven for 15 minutes. Then samples were quenched by treating with $3 \%$ hydrogen peroxide in methanol (endogenous peroxidase blocker) for 30 minutes and blocked with $5 \%$ bovine serum albumin (BSA) for 15 minutes. After above steps, samples were incubated with primary antibodies (1:1000, Bioss, Beijing, China) overnight, followed by incubation with secondary antibodies (1:1000, Bioss, Beijing, China). Subsequently, 3, 3'-diaminobenzidine tetrachloride (DAB) working solution was added to develop the samples. After counterstaining with hematoxylin, sections were dehydrated in ethanol, cleared in xylene, and sealed with resin. Pictures were taken with an Eclipse 
Ts2 microscope (Nikon, Japan), and then area of positive staining were quantified with Image J (NIH, US). Tumor and main organ sections were also counterstained with hematoxylin and eosin (H\&E, Beyotime, Shanghai, China). For detection of apoptotic cell death in tumor tissues, deparaffinized and rehydrated sections were subjected to TUNEL assay with a One Step TUNEL Apoptosis Assay Kit (Beyotime, Shanghai, China), following the manufacturer's instructions.

\subsection{Statistical Analysis}

All data were expressed as the means \pm SD from three independent experiments. Statistics were performed with Prism 5.0 statistical analysis software. After normality tests, the mean differences of groups were assessed with One-way analysis of variance (one-way ANOVA), followed by post hoc Student Newman-Keuls test. All statistical tests were two-sided, and $p<0.05$ was considered to have significance. Calculated $p$-values of $p<0.05, p<0.01$, and $p<0.001$ were as indicated.

\section{Results And Discussion}

\subsection{Antiproliferative Activity Evaluation in Vitro}

The in vitro antiproliferative efficacies of compound B8HA against MDA-MB-231, MDA-MB-468, MCF-7, 4T1, A549, HCT-116, HT-29 and K562 were evaluated with MTT assay. As shown in Table 1, compound B8HA showed considerable antiproliferative activities against MDA-MB-231, 4T1, MDA-MB-468, MCF-7, A549, HCT-116 after 48-hours incubation. Among the eight tested cancer cell lines, compound B8HA exhibited remarkable activity with the $\mathrm{IC}_{50}$ value of $4.2 \mu \mathrm{M}$ and $6.3 \mu \mathrm{M}$ for MDA-MB-231 and 4T1, respectively.

Table 1

Anti-proliferative activities of B8HA against eight tumor cell lines.

\begin{tabular}{|ll|}
\hline Tumor cell & IC $_{50} \pm \operatorname{SD}(\mu \mathrm{M})$ \\
\hline MDA-MB-231 & $4.2 \pm 0.5$ \\
\hline MDA-MB-468 & $10.1 \pm 0.3$ \\
MCF-7 & $18.6 \pm 1.3$ \\
\hline 4T1 & $6.3 \pm 1.2$ \\
A549 & $8.4 \pm 1.1$ \\
HCT-116 & $18.3 \pm 2.3$ \\
\hline HT-29 & $>50$ \\
\hline K562 & $30.2 \pm 0.6$ \\
\hline SD: standard deviation, all experiments were independently performed at least three times. \\
\hline
\end{tabular}




\subsection{Administration of B8HA Results in Significant Morphologic Changes}

Further illustrating the direct effects of B8HA on the growth of cancer cells, Fig. 2A showed the abundance of floating dead cells as well as the rough and lusterless appearance of remaining cells following B8HA administration. In addition, B8HA decreased the density of cells dose dependently, suggesting great sensitivities of cancer cells to B8HA. Therefore, MDA-MB-231 and 4T1 were selected for the remainder of our studies.

\subsection{B8HA Induce DNA Damage}

In order to determine whether DNA damage was induced under these conditions, the expression levels of $\mathrm{YH} 2 \mathrm{AX}$ were investigated. As shown in Fig. 2B, with the treatment of B8HA and SAHA, the expression of $\mathrm{YH} 2 \mathrm{AX}$ were remarkably enhanced in MDA-MB-231 and 4T1 cell lines. The results indicated that the compound B8HA as well as SAHA induced more DNA damages than CA-4 or control.

\subsection{B8HA Induced TNBC Apoptosis}

$\mathrm{B} 8 \mathrm{HA}$ is a potent $\mathrm{HDACi}$, thus the potential apoptotic effects were also evaluated. Dose-dependent increase of apoptosis by $11.91 \%, 18.2 \%$ and $32.05 \%$ at $0.1,1$ and $10 \mu \mathrm{M}$ of B8HA treatment were observed in B8HA treated MDA-MB-231 cells, respectively (Fig. 3A). Similarly, B8HA treatment induced $42.37 \%, 58.77 \%$ and $70.11 \%$ apoptosis in $4 \mathrm{~T} 1$ cells at $0.1,1$ and $10 \mu \mathrm{M}$, respectively. SAHA treatment (10 $\mu \mathrm{M}$ ) only induced $20.65 \%$ and $65.4 \%$ apoptosis of MDA-MB-231 and $4 \mathrm{~T} 1$ cells, respectively. Apparently, administration of B8HA was able to induce higher apoptosis rates as compared to the classical HDACi SAHA under the same dose.

Western blotting was used to evaluate the expression of apoptosis-related proteins (caspase-3 and PARP) (Fig. 3B). Comparing to mock-treated cells, remarkably increased expression levels of caspase-3 were observed in MDA-MB-231 and 4T1 cells treated with B8HA. Additionally, B8HA (1 or $10 \mu \mathrm{M})$ resulted in greater full length PARP loss than SAHA or CA-4, indicating a significant activation of the apoptotic cascade with this compound.

\subsection{Cell Cycle Arrest}

From previous reports, both HDAC and tubulin inhibition could result in cell cycle arrest ${ }^{17,18}$. As showed in Fig. 4, 4T1 and MDA-MB-231 cells were evidently arrested in G2/M phase by the treatment of B8HA in a concentration-dependent manner. It is clearly observed that the percentage of MDA-MB-231 cells in G2/M phase treated with B8HA increased from $19.9 \%$ (control) to $59.4 \%(2 \mu \mathrm{M})$ whereas the reference drug SAHA achieved $55.7 \%(2 \mu \mathrm{M})$. Similarly, the percentage of $4 \mathrm{~T} 1$ cells in $\mathrm{G} 2 / \mathrm{M}$ phase increased from 18.6$58.1 \%$ after treatment with B8HA at $2 \mu \mathrm{M}$, which was obviously more potent than SAHA (48.2\%). 


\subsection{Migratory and Invasion Capabilities Are Reduced with B8HA}

Wound healing assay and transwell assay were performed to assess the potential anti-migration activity of B8HA. As shown in Fig. 5A, there appeared to be a concentration-dependent inhibitory effect on in migration in MDA-MB-231 and 4T1 cells. MDA-MB-231 and 4T1 cells receiving $2 \mu \mathrm{M}$ doses of B8HA exhibited lower wound healing percent (37.7\% and 52.3\%) than SAHA ( $80 \%$ and $75 \%)$. Meanwhile, transwell assay showed similar results as the wound healing assay (Fig. 5B).

Invasion capabilities were evaluated with transwell inserts coated with Matrigel solution (Fig. 6). The results demonstrated that the ability of MDA-MB-231 cells to invade through the Matrigel matrix was significantly decreased following $2 \mu \mathrm{M}$ B8HA treatment (29\%) when compared with $2 \mu \mathrm{M}$ SAHA treatment (48\%). No significant differences of invasion capabilities of $4 T 1$ were detected between B8HA and SAHA. Taken together, these results suggested that B8HA may inhibit the migratory and invasive abilities of MDA-MB-231 and 4T1 cells in vitro and its inhibition capabilities are more potent than SAHA.

Western blotting was employed to identify the expressions of MMP2 and TIMP-2 proteins related to cell metastasis. As shown in Fig. 6B, the expressions of MMP2 protein were down-regulated in both MDA-MB231 and $4 \mathrm{~T} 1$ cells treated with B8HA. The level of MMP-2 expression was lower than positive control in 4T1 and equivalent to positive control in MDA-MB-231. Conversely, the expressions of TIMP-2 were significantly up-regulated, suggesting that B8HA treatment may affect migration and invasiveness through disturbing the degradation of extracellular matrix (ECM).

\subsection{Investigation of Antivascular Activity}

Firstly, the inhibitory effects on endothelial cell proliferation were determined after 48 hours of treatment with various concentrations of tested compounds (Fig. 7F). B8HA showed no drug-related toxicity to HUVEC at $1 \mu \mathrm{M}$. In contrast, Vincent et al reported that doses of CA-4 higher than $10 \mathrm{nM}$ had toxic effects in HUVEC cells, resulting in cell detachment and cell death ${ }^{19}$.

Then, we conducted an immunofluorescence assay to confirm its microtubule-destabilizing activities. As shown in Fig. 7A, normal arrangement and organization of microtubule structures, with microtubules extending from the central regions of the cell to the cell periphery, were observed in the control cells and cells treated with $2 \mu \mathrm{M}$ SAHA. In contrast, after exposure to $2 \mu \mathrm{M}$ B8HA for $24 \mathrm{~h}$, distinct abnormalities and disruptions appeared in the filaments. In this case HUVEC cells lost their typical elongated shape and appeared spherical and diffused.

Then two similar but distinct effects, antiangiogenic effects and vascular disrupting effects were evaluated. For the antiangiogenic effect, HUVEC cells were cultured in the presence of compounds on Matrigel while for vascular disrupting effects, the compounds were added only after HUVEC capillary 
network has formed. Endothelial cells seeded on Matrigel were able to form a capillary network mimicking the angiogenesis steps (A critical analysis of current in vitro and in vivo angiogenesis assays).

Antivascular properties of B8HA are observed at concentrations lower than those required to induce cell toxicity. Results of the antiangiogenic effects were shown in Fig. 7B. After six hours incubation, all the tested B8HA concentrations were effective in disrupting the tubule-like structures. In the control and SAHA group, the formation of a rich meshwork of branching capillary-like tubules with numerous junctions was evident. At the high concentrations of B8HA $(1 \mu \mathrm{M})$, the majority of HUVEC cells were spherical and aggregated in small clumps. An image analysis (Fig. 7E) was performed to obtain a quantitative measurement of the number of meshes and branching points, which showed that B8HA remarkably decreased tubule-like structures in a concentration- and time-dependent manner. Furthermore, the expression of VEGF was evaluated through western blotting assay (Fig. 7C). As compared with the control, the expression level of VEGF was decreased by B8HA treatment in a concentration dependent manner. The ability of B8HA to disrupt the "tubule-like" structures formed by HUVEC cells seeded on Matrigel were evaluated (Fig. 8A). After an hour incubation, $2 \mu \mathrm{M}$ B8HA visibly broke multicentric junctions of HUVEC cells, while there was no significant disruption in positive control (CA-4). After six hours incubation with $2 \mu \mathrm{M}$ B8HA, the networks of HUVEC cells were destroyed completely, which was similar to the positive control (CA-4). After nine hours incubation, there was still no disruption in SAHA group. These results showed that B8HA markedly destroyed tubule-like structures in a concentration- and time- dependent manner.

\subsection{In Vivo Antitumor Activity}

Due to the observed potent in vitro anti-proliferative activity of B8HA, a preliminary in vivo antitumor study was conducted in a tumor model developed in Balb/c mice. Antitumor effects and toxicities were evaluated through obtaining a quantitative measurement of body weight, tumor volume and tumor weight. As shown in Fig. 9A, B, C, after 2-week administration, B8HA at tested doses $(5,10,15 \mathrm{mg} / \mathrm{kg})$ resulted in a concentration-dependent reduction in tumor growth. The group of mice treated with 10 $\mathrm{mg} / \mathrm{kg} \mathrm{B8HA}$ had an average tumor growth inhibition (TGI) of $39 \%$ relative to control, and the group receiving $25 \mathrm{mg} / \mathrm{kg}$ doses averaged 57\% inhibition compared to control. However, the groups treated with $25 \mathrm{mg} / \mathrm{kg}$ SAHA or CA-4 only have a TGI of $23 \%$ and $32 \%$, respectively. These data indicated an appreciable improvement of the B8HA antitumor efficacy over SAHA and CA-4. Moreover, no significant body weight changes were observed in the B8HA-treated animals during the treatment period, indicating negligible acute toxicities at the doses tested (Fig. 9D).

To assess necrotic and apoptotic effects in tumor tissue, the sections were fixed and examined with the H\&E and TUNEL staining (Fig. 9F). H\&E staining of tumor sections from saline group revealed aggressive growth with abundant mitotic cells in different stages. After administration of B8HA, there were significantly less proliferation and numerous apoptotic cells showing dense nuclear pyknosis and cytoplasmic karyorrhexis. In TUNEL staining, the percentage of apoptotic cells was determined by cell counting. The results indicated that the percentage of TUNEL-positive tumor cells were obviously lower in 
SAHA $(25 \mathrm{mg} / \mathrm{kg})$ and CA-4 $(25 \mathrm{mg} / \mathrm{kg})$ groups than those in the B8HA group $(25 \mathrm{mg} / \mathrm{kg})$. These observations were further confirmed by immunohistochemistry staining.

Ki-67 staining of tumor sections from control group showed few positive regions, while tumor sections in the $25 \mathrm{mg} / \mathrm{kg}$ B8HA-treated group showed an increase in Ki-67 positive labeled cells, suggesting tumor suppressive effect (Fig. 10). Furthermore, there were increased $\mathrm{yH} 2 \mathrm{AX}$ positive cell in the B8HA-treated group, indicating induction of significant DNA damage and inhibition of DNA repair. Then, antivascular activity was investigated through evaluating the expression of VEGF and CD-31. Comparing to the untreated mice and CA-4 $(25 \mathrm{mg} / \mathrm{kg})$ treated mice, tumor sections from B8HA group displayed severely destroyed blood vessels or absence of VEGF and CD-31 positive cells, confirming potential antivascular properties of B8HA. In addition, the expression of metastasis-related protein MMP-2 was obviously inhibited in B8HA treated tumor tissue.

To evaluate whether B8HA treatment produces potential organ toxicities, histological analysis was conducted on major organ including heart, liver, spleen, lung and kidney (Fig. 11). H\&E staining revealed no apparent histological changes in all B8HA treatment groups. These results were consistent with previous in vitro observations and suggested that B8HA is well-tolerated for doses up to $25 \mathrm{mg} / \mathrm{kg}$ in mice and can efficiently inhibit the process of TNBC.

\section{Discussion}

In a previous study, Wang et al. designed and synthesized a series of tubulin/HDAC hybrid inhibitors. Among these compounds, B8HA exhibited promising potency for cancer treatment. In the current study, we further demonstrated that compound B8HA presented superior HDAC and tubulin inhibition properties for TNBC both in vitro and in vivo, in comparison to HDACi SAHA and tubulin binding agents CA-4.

It is well known that HDACs play crucial roles in cancer by deacetylating histone and nonhistone proteins 8 , which are involved in DNA damage repair, apoptosis, cell cycle, metastasis, angiogenesis, differentiation, and other cellular processes ${ }^{20}$. Numerous studies have demonstrated that HDACs have important roles in DNA-damage repair responses because HDACs are critical in modulating chromatin remodeling and maintaining dynamic acetylation equilibrium of DNA-damage-related proteins ${ }^{21}$. We observed that B8HA as well as SAHA have a strong potency to induce DNA damage and suppress DNA repair in vitro and in vivo ${ }^{22}$. This effect could contribute to the observed apoptotic effects ${ }^{23}$. Treatment of tumor cells with HDACi can either directly induce apoptosis through the extrinsic (death receptor)/intrinsic (mitochondria) pathway, or enhance the susceptibility of tumor cells to apoptosis, which converged at the activation of caspases ${ }^{24}$. Comparing to the classical HDACi SAHA, B8HA was able to induce more prominent apoptosis under the same dose as supported by upregulation of caspase3 and PARP cleavage in MDA-MB-231 and 4T1 cells. On the other hand, apoptosis is also a consequence of mitotic blockade and abnormal mitotic exit. For example, tubulin binding agents, colchicine, at microtubules-depolymerizing concentrations $(2 \mu \mathrm{M})$, also could induce apoptosis in human leukemia cells ${ }^{25}$, which is the major reason for the superior potency of B8HA compared to SAHA. 
Epithelial-to-mesenchymal transition (EMT) is a major process in cancer cell invasion and metastasis. HDACs play a key role in EMT regulation in a variety of tumors ${ }^{26}$. We found that B8HA dose-dependently inhibited the migratory and invasive abilities of MDA-MB-231 and 4T1 cells in vitro with higher potency than SAHA. Recent study showed that treatment of cells with the HDACs inhibitor, LBH589 (panobinostat), represses EMT and metastasis through inducing $\mathrm{CDH} 1$ expression in TNBC cells ${ }^{27}$, which may explain the anti-metastatic properties of B8HA. These findings indicated the therapeutic potential of B8HA in inhibiting metastasis of cancer cells.

B8HA also displayed microtubule-destabilizing activities due to the structures based on potent microtubule-destabilizing agents. CA-4 and B8HA exhibited negligible cytotoxicity at $10 \mathrm{nM}$ and $2 \mu \mathrm{M}^{19}$. Therefore, overt cytotoxicity is unlikely the mechanism for B8HA-induced anti-vascular activity. We found that B8HA as well as CA-4 could cause the disintegration of intracellular microtubule networks, which would potentially lead to cell cycle disorder ${ }^{28}$. It is also known that microtubule-targeting agents suppress microtubule dynamics leading to cell cycle arrest at the mitotic phase ${ }^{29}$. In cell cycle analysis, cells were arrested in $\mathrm{G} 2 / \mathrm{M}$ phase after treatment with B8HA, confirming that the mechanism of action of B8HA was through destabilization of microtubules.

Moreover, the disruption of microtubule structure has a negative effect on angiogenesis. Microtubuledestabilizing agents work by disrupting the endothelial cells' reliance on the tubulin cytoskeleton to maintain their shape. The subsequent change in endothelial shape leads to vessel blockage, reduced blood flow and disruption of the endothelial cell layer, resulting in exposure of the basement membrane and increased vessel permeability ${ }^{30}$. The results showed that B8HA was able to inhibit the formation of capillary-like structures as well as to disrupt existing tubules, suggesting that it have both antiangiogenic and vascular disrupting effects.

In our study, we also confirmed that the administration of B8HA could suppress the tumor growth much more effectively than SAHA and CA-4 in 4T1 tumor-bearing mice at the same dose. Moreover, there were no significant differences in body weight of all groups during treatment period, indicating negligible acute toxicities and good safety margin. H\&E staining of tumors tissues received B8HA treatment showed the lowest proliferation where abundant apoptotic cells with showed dense nuclear pyknosis and cytoplasmic karyorrhexis. TUNEL assay revealed a significant increase of TUNEL-positive (apoptosis) cells in B8HA-treated group, as compared to SAHA and CA-4. The exciting in vivo antitumor efficacy of B8HA over that of SAHA and CA-4 could be ascribed to the combination of HDAC and tubulin inhibition. Sustained angiogenesis is one of the central hallmarks of cancer and has been validated as a key target for cancer therapy ${ }^{31}$. For instance, tubulin-targeting agent DW532 showed potent anti-angiogenesis activity in vivo as evidenced by the inhibition of the blood vessel formation in chick chorioallantoic membrane assay ${ }^{17}$. The B8HA treatment groups displayed severely distorted blood vessels and absence of VEGF positive staining, suggesting its potential vascular disrupting properties. We also examined the expression of Ki-67, a well-known marker of cell proliferation and poor prognosis. It was identified that the treatment of $\mathrm{B} 8 \mathrm{HA}$ was accompanied by a reduction in cell proliferation, as indicated by lower numbers 
of Ki-67-positive cells. This finding is in accordance with a recent study, in which HDAC1/2 inhibitor Romidepsin-mediated Ki-67 expression suppression in hepatocellular carcinoma mice was reported ${ }^{32}$. In addition, previous studies had shown that HDACi MS-275 and SAHA all downregulated the expression of MMP-2 in MDA-MB-468 tumor tissues as well as inhibited the lung metastasis ${ }^{33}$. We demonstrated that the treatment of mice with B8HA resulted in the more prominent inhibition of MMP-2 compared with that of CA-4 and SAHA. H\&E staining revealed no apparent histological changes in main organs obtained from treatment groups, which were consistent with the absence of significant body weight changes of mice.

In summary, the novel HDAC/tubulin dual-targeting inhibitor B8HA were investigated for anti-tumor activities. B8HA displayed potent anti-HDAC activity, even more potent than the classical HDACi, SAHA. On the other hand, B8HA also has microtubule-destabilizing activities due to the structures based on potent microtubule-destabilizing agents. We established that B8HA were capable of directly interfering with angiogenic events, since B8HA completely inhibited the formation of tubule-like structures in a concentration-dependent manner. Furthermore, B8HA had superior antitumor efficacy and antiangiogenesis activity than SAHA and CA-4 in 4T1 mice model under the same dose without causing apparent toxicity to major organs, and possessed a good safety profile. Collectively, B8HA showed robust in vitro and in vivo anti-tumor efficacy against TNBC, paving the way for its further development as a promising drug candidate.

\section{Declarations}

Ethics approval and consent to participate Experiments and care/welfare were in agreement with a protocol approved by the Qingdao University Animal Studies Committee.

Consent for publication Not applicable.

Availability of data and materials All data generated or analysed during this study are included in this published article.

Competing interests The authors declare that they have no competing interests.

Funding This work is funded by Shandong Provincial Natural Science Foundation (ZR2021MH190).

Authors' contributions KL performed in vivo experiments, western blotting, antivascular experiments. QZ performed FACS analysis and transwell assay. SQ performed in vitro cell cytotoxicity and wound healing assay. YX performed in vivo antitumor activity. XC supervised the project, analyzed the results and wrote the manuscript.

Acknowledgements Not applicable.

Disclosure of potential conflicts of interest All authors declare no conflict of interest. 
Research involving Human Participants and/or Animals All applicable international, national, and/or institutional guidelines for the care and use of animals were followed. All procedures performed in the studies involving human participants were in accordance with the ethical standards of the institutional and/or national research committee and with the 1964 Helsinki declaration and its later amendments or comparable ethical standards.

Informed consent Not applicable.

\section{References}

1. Bianchini G, Balko JM, Mayer IA, Sanders ME, Gianni L Triple-negative breast cancer: challenges and opportunities of a heterogeneous disease.Nat Rev Clin Oncol2016, 13 (11),674-690. DOI:

10.1038/nrclinonc.2016.66

2. Foulkes WD, Smith IE, Reis-Filho JS (2010) Triple-negative breast cancer. N Engl J Med 363(20):1938-1948. DOI: 10.1056/NEJMra1001389

3. Siegel RL, Miller KD, Jemal A (2019) Cancer statistics, 2019. CA Cancer J Clin 69(1):7-34. DOI: 10.3322/caac. 21551

4. Gradishar WJ, Anderson BO, Balassanian R, Blair SL, Burstein HJ, Cyr A, Elias AD, Farrar WB, Forero A, Giordano SH et al (2016) NCCN Guidelines Insights Breast Cancer, Version 1. J Nat/ Compr Canc Netw 2015, 13 (12), 1475-1485. DOI: 10.6004/jnccn.2015.0176. Gu, G.; Dustin, D.; Fuqua, S. A. Targeted therapy for breast cancer and molecular mechanisms of resistance to treatment. Curr Opin Pharmacol 2016, 31, 97-103. DOI: 10.1016/j.coph.2016.11.005

5. Garmpis N, Damaskos C, Garmpi A, Kalampokas E, Kalampokas T, Spartalis E, Daskalopoulou A, Valsami S, Kontos M, Nonni A et al Histone Deacetylases as New Therapeutic Targets in Triplenegative Breast Cancer: Progress and Promises. Cancer Genomics Proteomics2017, 14 (5),299-313. DOI: $10.21873 /$ cgp. 20041

6. Marks DL, Olson RL, Fernandez-Zapico ME (2016) Epigenetic control of the tumor microenvironment. Epigenomics 8(12):1671-1687. DOI: 10.2217/epi-2016-0110

7. Xiaowei Yang ATF, Sharyl J, Nass DL, Phillips, Kim A, Butash SM, Wang JG, Herman, Nancy E, Li A, Liu Z, Li M, Zhou S, Xu Y, Xiao Y, Yang W (2000) 60 (24), 6890-6894. Zhang, Z.; Yamashita, H.; Toyama, T.; Sugiura, H.; Ando, Y.; Mita, K.; Hamaguchi, M.; Hara, Y.; Kobayashi, S.; Iwase, H. Quantitation of HDAC1 mRNA expression in invasive carcinoma of the breast*. Breast Cancer Res Treat 2005, 94 (1), 11-16. DOI: 10.1007/s10549-005-6001-1. Li A, Liu Z, Li M, Zhou S, Xu Y, Xiao Y, Yang W HDAC5, a potential therapeutic target and prognostic biomarker, promotes proliferation, invasion and migration in human breast cancer. Oncotarget 2016, 7(25), 37966-37978. DOI: 10.18632/oncotarget.9274

8. Yoon S, Eom GH, HDAC, Inhibitor HDAC (2016) From Cancer to Cardiovascular Diseases. Chonnam Med J 52(1):1-11. DOI: 10.4068/cmj.2016.52.1.1 
9. Anighoro A, Bajorath J, Rastelli G (2014) 57 (19), 7874-7887. DOI: 10.1021/jm5006463. Shang, E.; Yuan, Y.; Chen, X.; Liu, Y.; Pei, J.; Lai, L. De novo design of multitarget ligands with an iterative fragment-growing strategy. J Chem Inf Model 2014, 54 (4), 1235-1241. DOI: 10.1021/ci500021v

10. Fu RG, Sun Y, Sheng WB, Liao DF, Stark E, Merk H (2017) 136, 195-211. DOI:

10.1016/j.ejmech.2017.05.016. Anastasio, T. J. Editorial: Computational and Experimental Approaches in Multi-target Pharmacology. Front Pharmacol 2017, 8, 443. DOI:

10.3389/fphar.2017.00443. Proschak, Stark E, Merk H, D. Polypharmacology by Design: A Medicinal Chemist's Perspective on Multitargeting Compounds. J Med Chem 2019, 62 (2), 420-444. DOI: 10.1021/acs.jmedchem.8b00760. Bolognesi, M. L. Harnessing Polypharmacology with Medicinal Chemistry. ACS Med Chem Lett 2019, 10 (3), 273-275. DOI: 10.1021/acsmedchemlett.9b00039

11. Hesham HM, Lasheen DS, Abouzid KAM Chimeric HDAC inhibitors: Comprehensive review on the HDAC-based strategies developed to combat cancer.Med Res Rev2018, 38 (6),2058-2109. DOI: $10.1002 /$ med.21505

12. Chao MW, Lai MJ, Liou JP, Chang YL, Wang JC, Pan SL, Teng CM (2015) The synergic effect of vincristine and vorinostat in leukemia in vitro and in vivo. J Hematol Oncol 8:82. DOI: 10.1186/s13045-015-0176-7

13. Zhang X, Zhang J, Tong L, Luo Y, Su M, Zang Y, Li J, Lu W, Chen Y (2013) The discovery of colchicine-SAHA hybrids as a new class of antitumor agents. Bioorg Med Chem 21(11):3240-3244. DOI: 10.1016/j.bmc.2013.03.049

14. Zhang X, Kong Y, Zhang J, Su M, Zhou Y, Zang Y, Li J, Chen Y, Fang Y, Zhang X et al (2015) Design, synthesis and biological evaluation of colchicine derivatives as novel tubulin and histone deacetylase dual inhibitors. Eur J Med Chem 95:127-135. DOI: 10.1016/j.ejmech.2015.03.035

15. Lamaa D, Lin HP, Zig L, Bauvais C, Bollot G, Bignon J, Levaique H, Pamlard O, Dubois J, Ouaissi M et al (2018) Design and Synthesis of Tubulin and Histone Deacetylase Inhibitor Based on isoCombretastatin A-4. J Med Chem 61(15):6574-6591. DOI: 10.1021/acs.jmedchem.8b00050

16. Wang B, Chen X, Gao J, Su L, Zhang L, Xu H, Luan Y Anti-tumor activity evaluation of novel tubulin and HDAC dual-targeting inhibitors.Bioorg Med Chem Lett2019, 29 (18),2638-2645. DOI: 10.1016/j.bmcl.2019.07.045

17. Peng T, Wu JR, Tong LJ, Li MY, Chen F, Leng YX, Qu R, Han K, Su Y, Chen Y et al (2014) Identification of DW532 as a novel anti-tumor agent targeting both kinases and tubulin. Acta Pharmacol Sin 35(7):916-928. DOI: 10.1038/aps.2014.33

18. Ma YM, Zhou YB, Xie CM, Chen DM, Li J (2012) Novel microtubule-targeted agent 6-chloro-4(methoxyphenyl) coumarin induces G2-M arrest and apoptosis in HeLa cells. Acta Pharmacol Sin 33(3):407-417. DOI: 10.1038/aps.2011.176

19. Vincent L, Kermani P, Young LM, Cheng J, Zhang F, Shido K, Lam G, Bompais-Vincent H, Zhu Z, Hicklin DJ et al (2005) Combretastatin A4 phosphate induces rapid regression of tumor neovessels and growth through interference with vascular endothelial-cadherin signaling. J Clin Invest 115(11):2992-3006. DOI: 10.1172/JCl24586 
20. Tang F, Choy E, Tu C, Hornicek F, Duan Z (2017) 59, 33-45. DOI: 10.1016/j.ctrv.2017.06.006. Paris, M.; Porcelloni, M.; Binaschi, M.; Fattori, D. Histone deacetylase inhibitors: from bench to clinic. J Med Chem 2008, 51 (6), 1505-1529. DOI: 10.1021/jm7011408

21. Roos WP, Krumm A (2016) The multifaceted influence of histone deacetylases on DNA damage signalling and DNA repair. Nucleic Acids Res 44 (21), 10017-10030. DOI: 10.1093/nar/gkw922. Lee, J. H.; Choy, M. L.; Ngo, L.; Foster, S. S.; Marks, P. A. Histone deacetylase inhibitor induces DNA damage, which normal but not transformed cells can repair. Proc Natl Acad Sci U S A 2010, 107 (33), 14639-14644. DOI: 10.1073/pnas.1008522107

22. Kopp B, Khoury L, Audebert M (2019) 93 (8), 2103-2114. DOI: 10.1007/s00204-019-02511-9. Valdiglesias, V.; Giunta, S.; Fenech, M.; Neri, M.; Bonassi, S. gammaH2AX as a marker of DNA double strand breaks and genomic instability in human population studies. Mutat Res 2013, 753 (1), 24-40. DOI: 10.1016/j.mrrev.2013.02.001

23. Gaymes TJ, Padua RA, Pla M, Orr S, Omidvar N, Chomienne C, Mufti GJ, Rassool FV (2006) 4 (8), 563-573. DOI: 10.1158/1541-7786.MCR-06-0111. Munshi, A.; Kurland, J. F.; Nishikawa, T.; Tanaka, T.; Hobbs, M. L.; Tucker, S. L.; Ismail, S.; Stevens, C.; Meyn, R. E. Histone deacetylase inhibitors radiosensitize human melanoma cells by suppressing DNA repair activity. Clin Cancer Res 2005, 11 (13), 4912-4922. DOI: 10.1158/1078-0432.CCR-04-2088

24. Van Opdenbosch N, Lamkanfi M (2019) Caspases in Cell Death, Inflammation, and Disease. Immunity 50(6):1352-1364. DOI: 10.1016/j.immuni.2019.05.020

25. Martin SJ, Cotter TG (1990) Disruption of microtubules induces an endogenous suicide pathway in human leukaemia HL-60 cells. Cell Tissue Kinet 23(6):545-559. DOI: 10.1111/j.13652184.1990.tb01345.x

26. Bian X, Liang Z, Feng A, Salgado E, Shim H, Beus I, Stochaj M, Le U, Zorc PU, Rajic B, Petrecca Z, Maysinger K (2018) 147, 30-37. DOI: 10.1016/j.bcp.2017.11.008. Park, S. Y.; Jun, J. A.; Jeong, K. J.; Heo, H. J.; Sohn, J. S.; Lee, H. Y.; Park, C. G.; Kang, J. Histone deacetylases 1, 6 and 8 are critical for invasion in breast cancer. Oncol Rep 2011, 25 (6), 1677-1681. DOI: 10.3892/or.2011.1236. Zhang, Beus I, Stochaj M, Le U, Zorc PU, Rajic B, Petrecca Z, Maysinger K, D. Inhibition of glioblastoma cell proliferation, invasion, and mechanism of action of a novel hydroxamic acid hybrid molecule. Cell Death Discov 2018, 4, 41. DOI: 10.1038/s41420-018-0103-0

27. Rhodes LV, Tate CR, Segar HC, Burks HE, Phamduy TB, Hoang V, Elliott S, Gilliam D, Pounder FN, Anbalagan $\mathrm{M}$ et al (2014) Suppression of triple-negative breast cancer metastasis by pan-DAC inhibitor panobinostat via inhibition of ZEB family of EMT master regulators. Breast Cancer Res Treat 145(3):593-604. DOI: 10.1007/s10549-014-2979-6

28. Jordan MA, Wilson L (2004) Microtubules as a target for anticancer drugs. Nat Rev Cancer 4(4):253265. DOI: $10.1038 / \mathrm{nrc13} 17$

29. Chun $P$ (2015) Histone deacetylase inhibitors in hematological malignancies and solid tumors. Arch Pharm Res 38(6):933-949. DOI: 10.1007/s12272-015-0571-1 
30. Patterson DM, Rustin GJ (2007) Vascular damaging agents. Clin Oncol (R Coll Radiol) 19 (6), 443456. DOI: 10.1016/j.clon.2007.03.014. Siemann, D. W. The unique characteristics of tumor vasculature and preclinical evidence for its selective disruption by Tumor-Vascular Disrupting Agents. Cancer Treat Rev 2011, 37 (1), 63-74. DOI: 10.1016/j.ctrv.2010.05.001

31. Hanahan D, Weinberg RA (2011) 144 (5), 646-674. DOI: 10.1016/j.cell.2011.02.013. Li, T.; Kang, G.; Wang, T.; Huang, $\mathrm{H}$. Tumor angiogenesis and anti-angiogenic gene therapy for cancer. Oncol Lett 2018, 16 (1), 687-702. DOI: 10.3892/ol.2018.8733

32. Afaloniati H, Angelopoulou K, Giakoustidis A, Hardas A, Pseftogas A, Makedou K, Gargavanis A, Goulopoulos T, Iliadis S, Papadopoulos V et al (2020) HDAC1/2 Inhibitor Romidepsin Suppresses DEN-Induced Hepatocellular Carcinogenesis in Mice. Onco Targets Ther 13:5575-5588. DOI: 10.2147/OTT.S250233

33. Srivastava RK, Kurzrock R, Shankar S (2010) MS-275 sensitizes TRAIL-resistant breast cancer cells, inhibits angiogenesis and metastasis, and reverses epithelial-mesenchymal transition in vivo. Mol Cancer Ther 9(12):3254-3266. DOI: 10.1158/1535-7163.MCT-10-0582

\section{Figures}

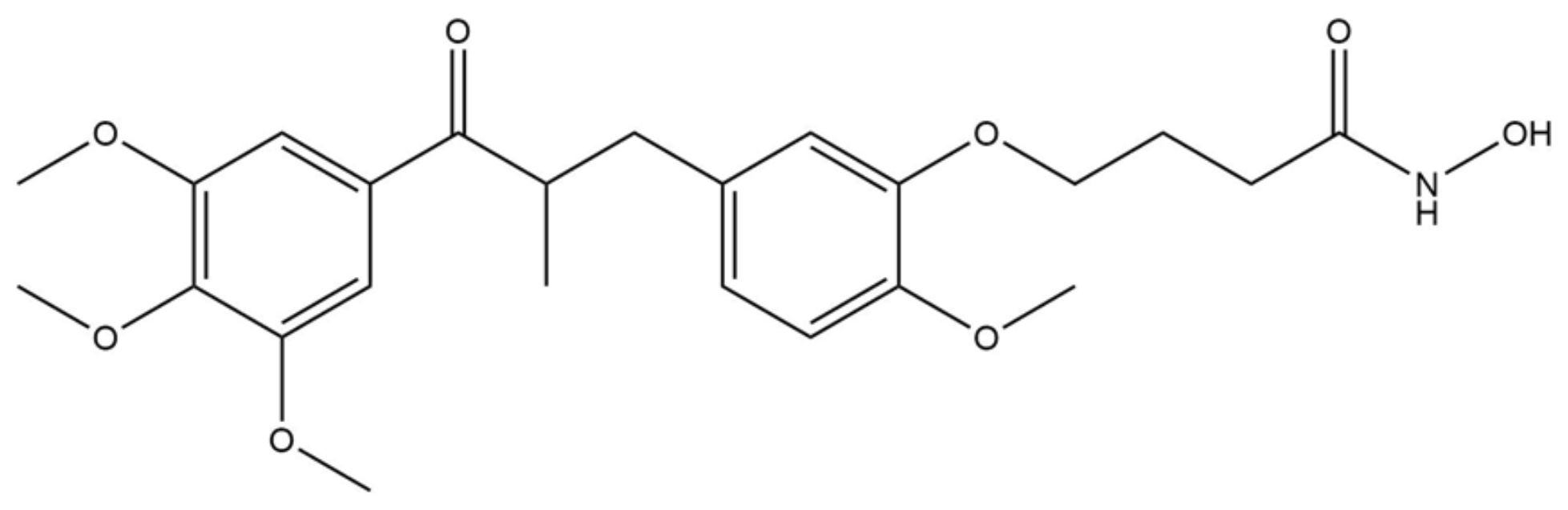

\section{Figure 1}

Tubulin and HDAC dual-target inhibitor B8HA. 
A

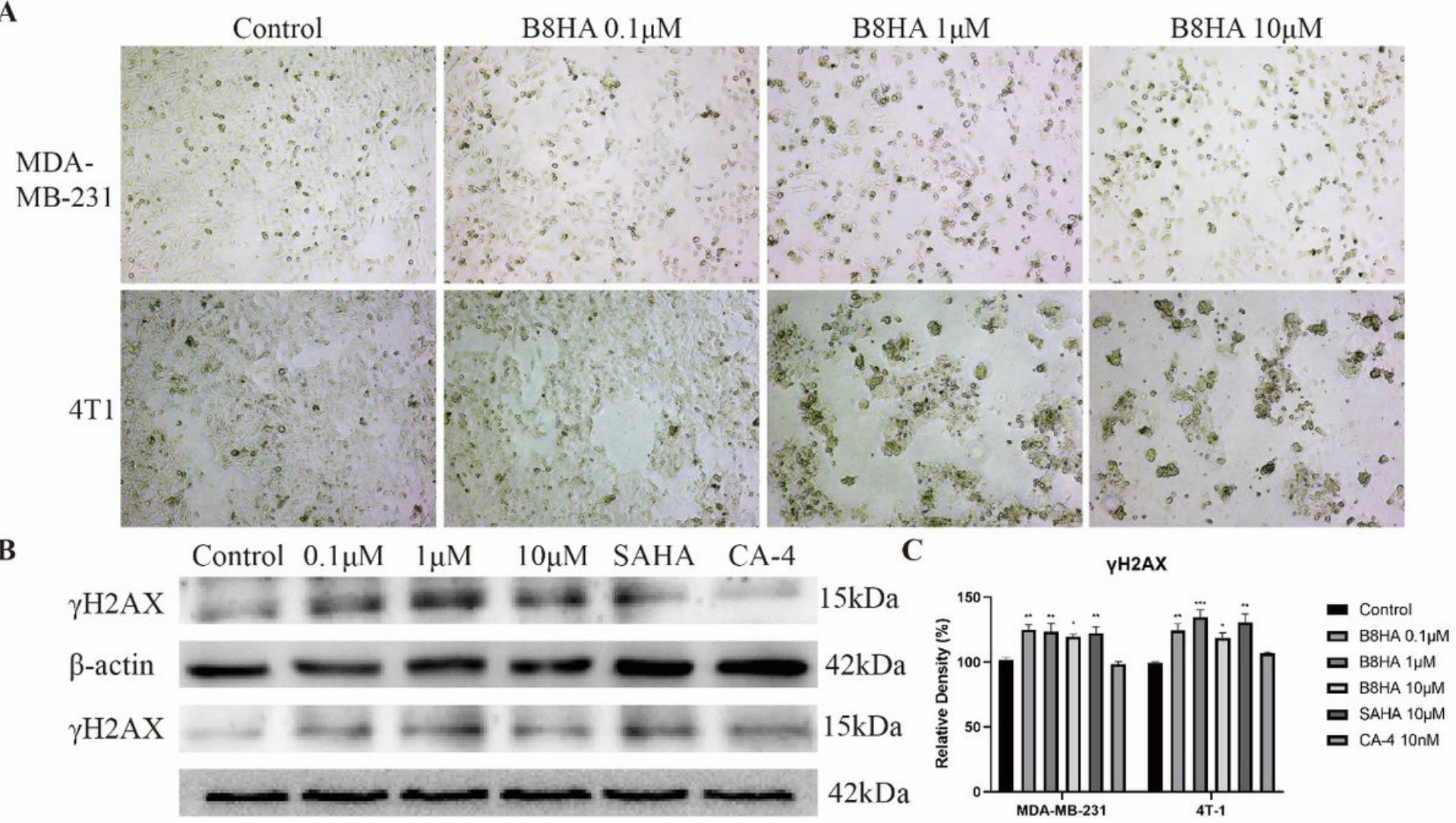

Figure 2

(A) The morphology of MDA-MB-231 and 4T1 cells treated with different concentrations of B8HA. Images were captured under a bright field at 20x magnification. $(B, C)$ The investigation of $y H 2 A X$ in MDA-MB231 and 4 T1 cells by WB. ${ }^{*} \mathrm{P}<0.05,{ }^{* *} \mathrm{P}<0.01,{ }^{*} * * \mathrm{P}<0.001$ compared with control. 


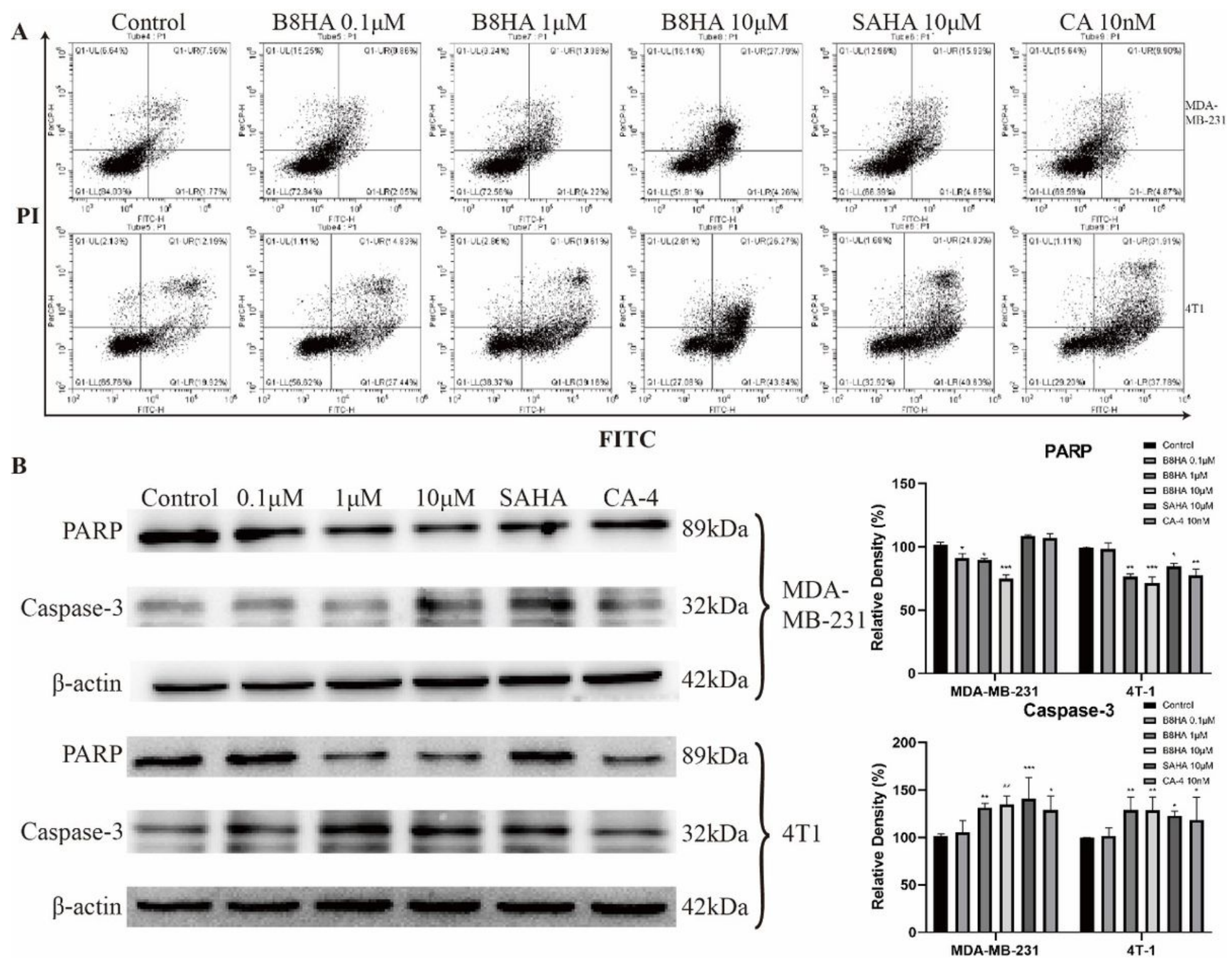

Figure 3

(A) Flow cytometry analysis of apoptosis of MDA-MB-231 and 4T1 cells after treatment with B8HA, SAHA and CA-4. (B) Detection of PARP and caspase-3 quantities in cells by WB. ${ }^{*} P<0.05,{ }^{*} P<0.01,{ }^{\star * \star} P<0.001$ compared with control. 
A
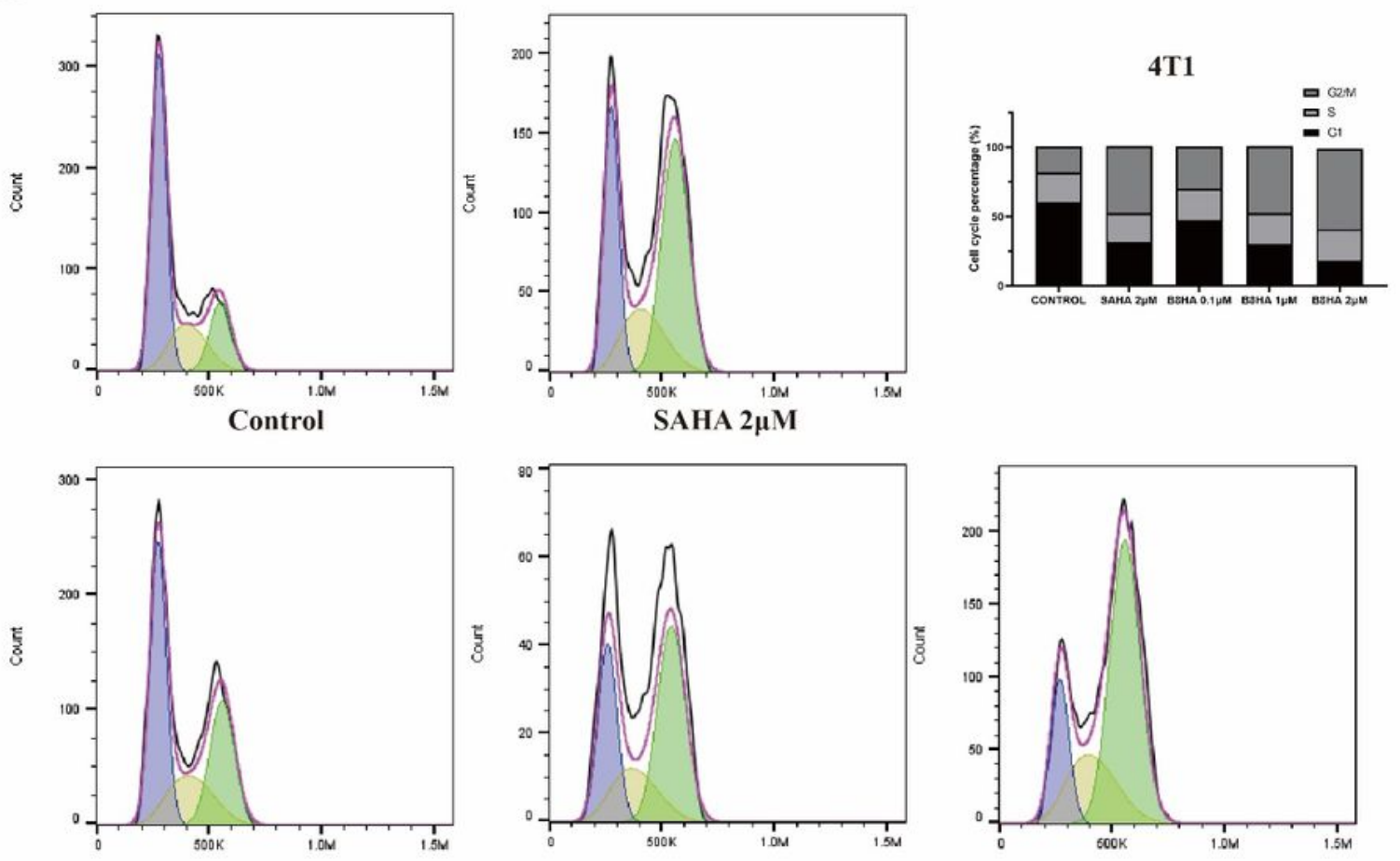

B

B8HA 0.1 $\mu$ M

B8HA $1 \mu \mathrm{M}$
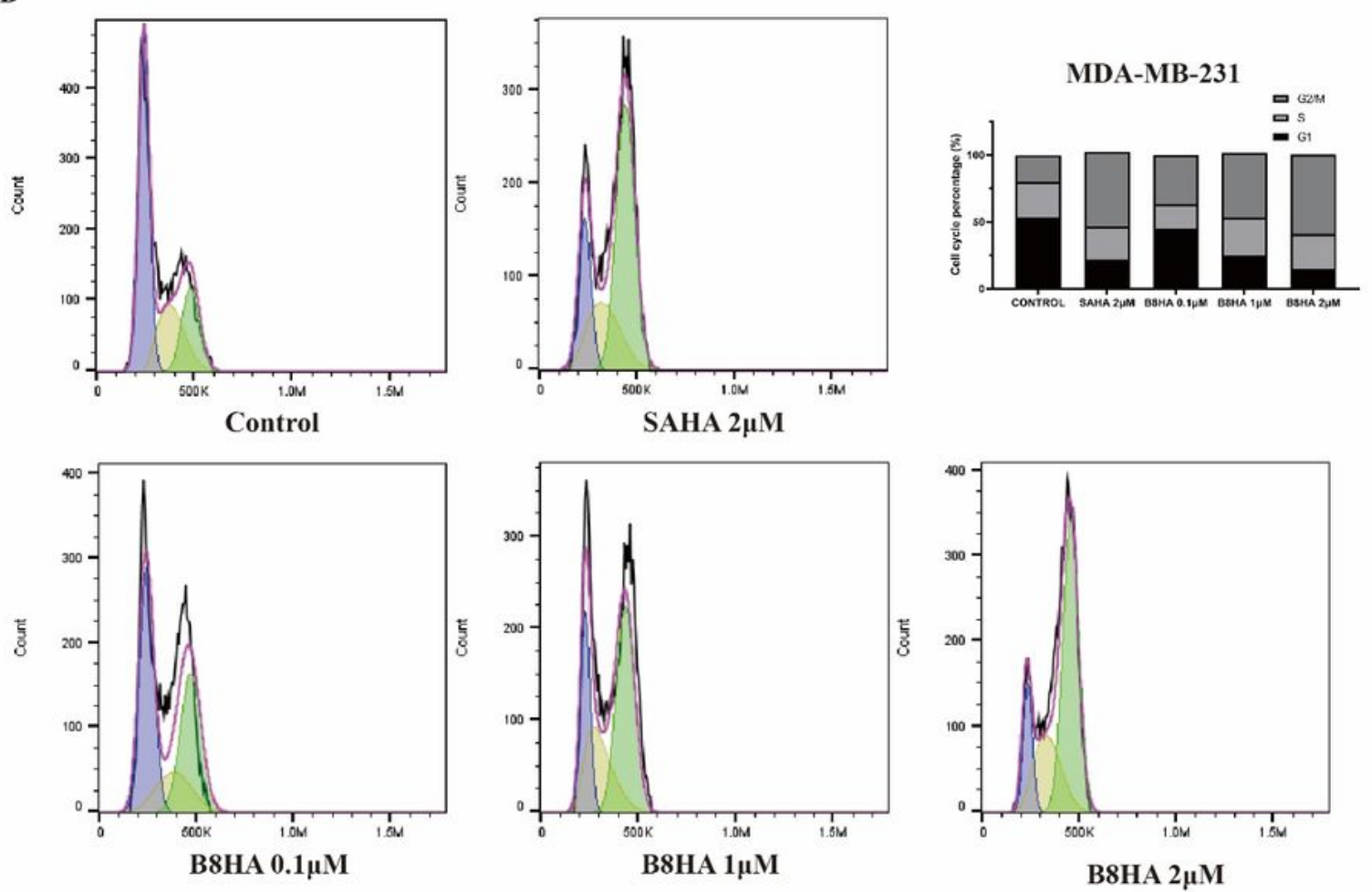

Figure 4

Cell cycle analysis in 4T1(A) and MDA-MB-231(B) cells after incubation with different formulations for $24 \mathrm{~h}$. 


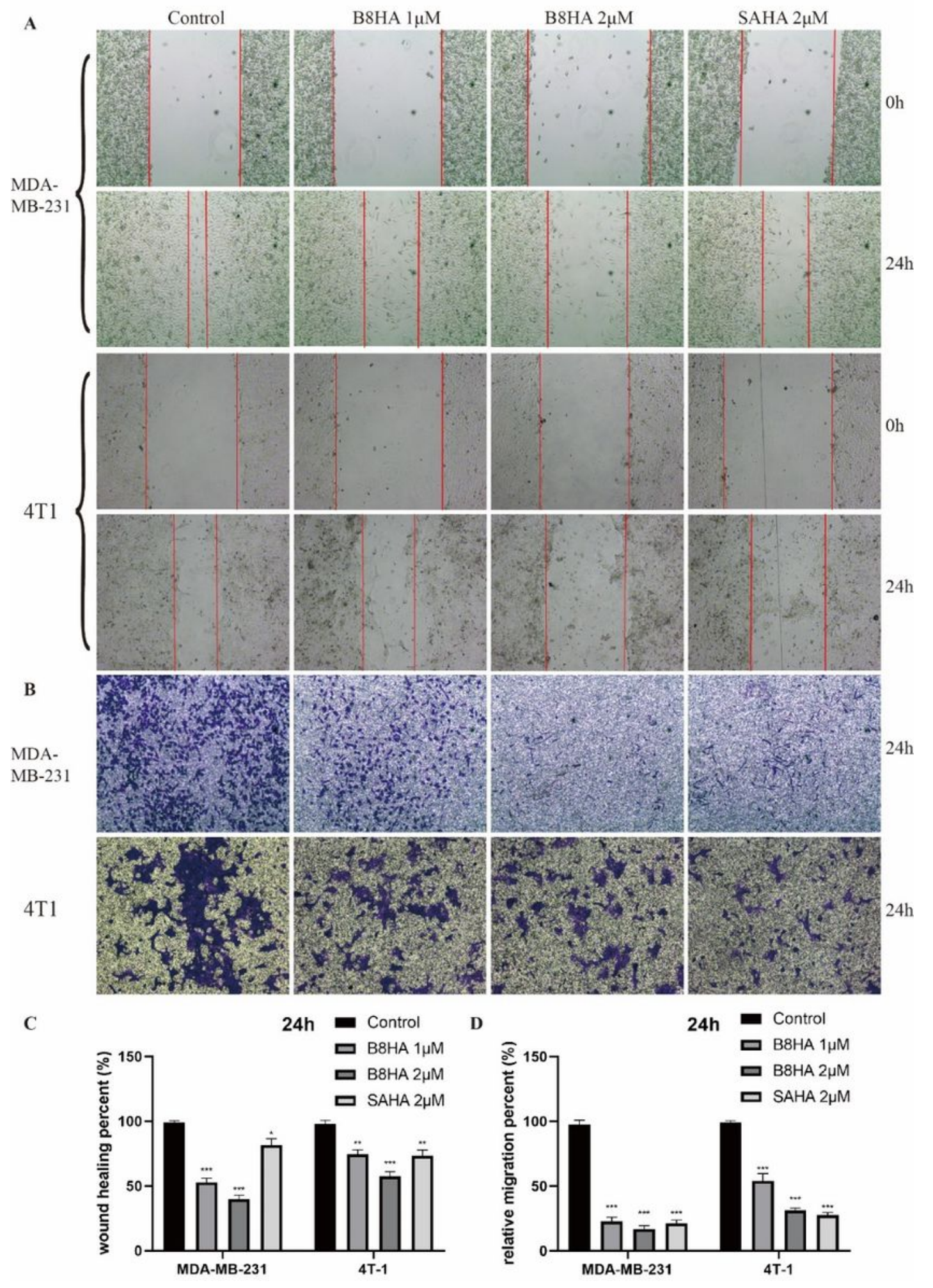

Figure 5

The effect of B8HA on migration of MDA-MB-231 and 4T1 cells was detected by wound healing assay and transwell assay. (A) MDA-MB-231 and 4T1 cells were treated with 1 and $2 \mu \mathrm{M}$ of B8HA and $2 \mu \mathrm{M}$ of SAHA for 24 hours, then (B) the migration ability of the cells was detected by wound healing assay and transwell assay. (C, D) The graph shows the quantitative effect of B8HA. Migration was quantified by 
measuring the gap closure and the average number of migrating cells. Images were captured under a bright field at $10 x$ magnification. ${ }^{*} P<0.05,{ }^{\star *} P<0.01,{ }^{\star \star \star} P<0.001$ compared with control.

A

Control

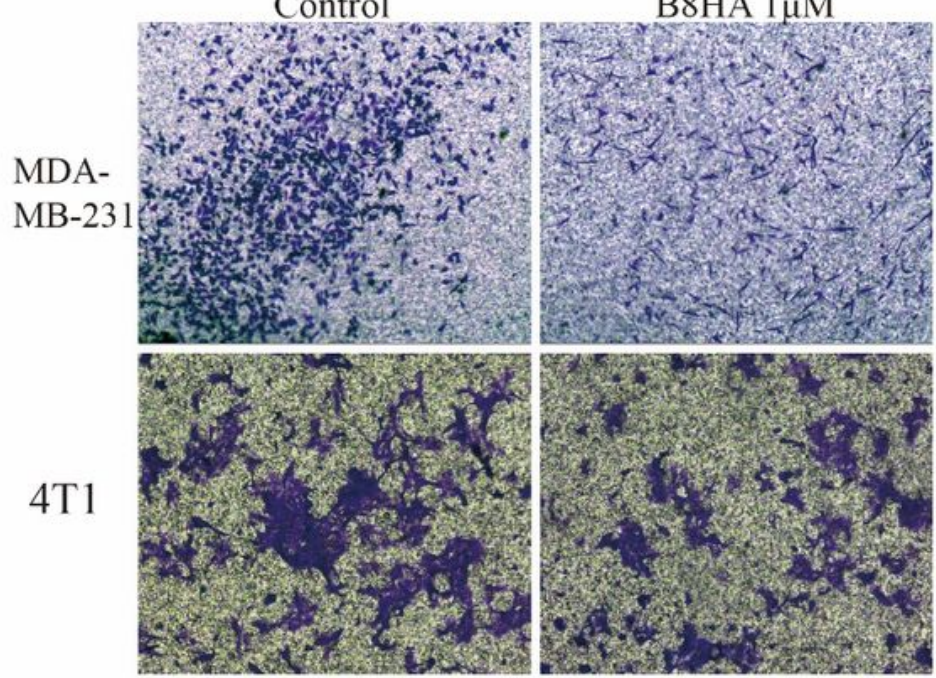

B8HA $2 \mu \mathrm{M}$

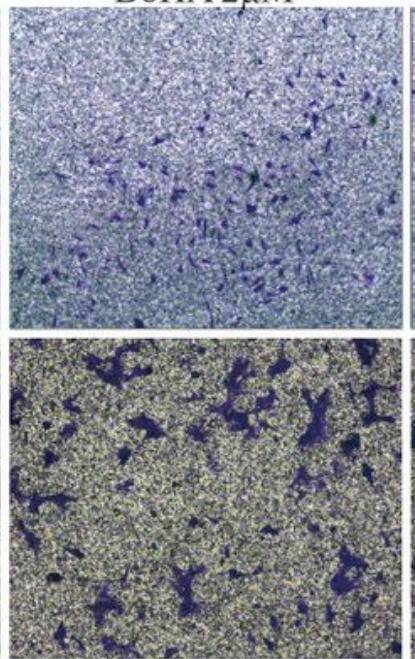

C
SAHA $2 \mu \mathrm{M}$

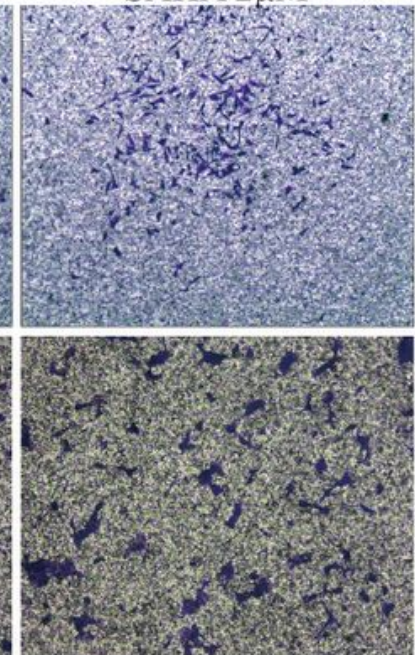

B

$$
\text { Control } \quad 0.1 \mu \mathrm{M} \quad 1 \mu \mathrm{M} \quad 10 \mu \mathrm{M} \quad \text { SAHA } \quad \mathrm{CA}-4
$$

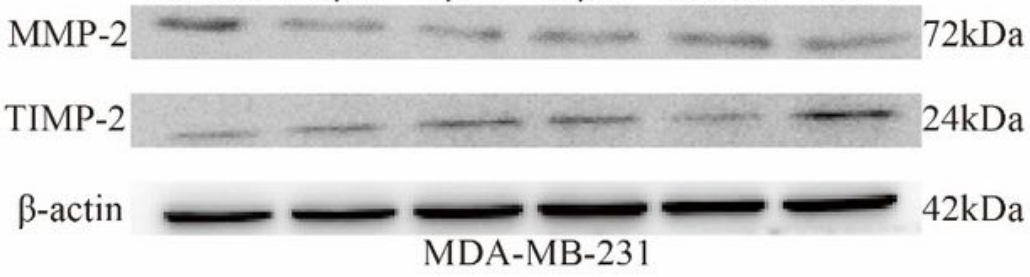

MMP-2

$72 \mathrm{kDa}$

\section{TIMP-2}

$\beta$-actin

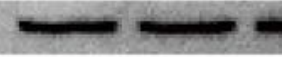

$4 \mathrm{~T} 1$

D

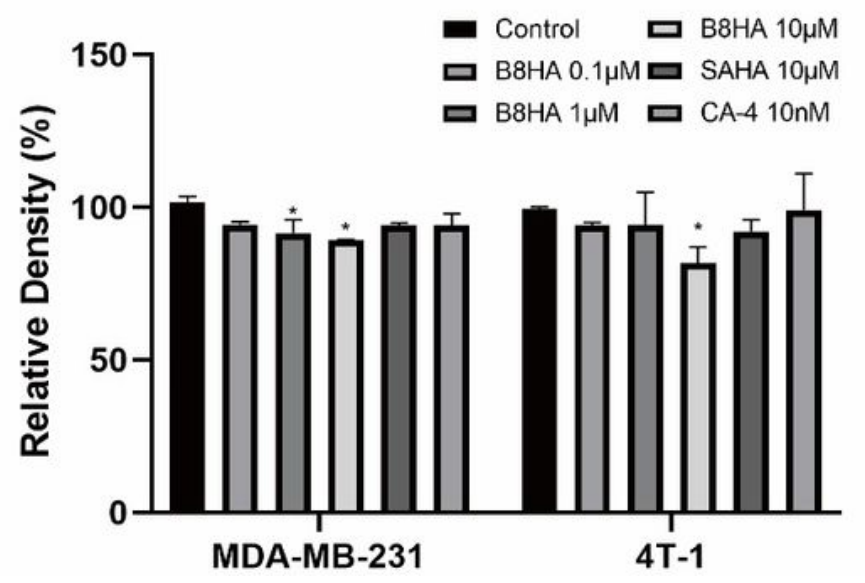

$\mathbf{E}$

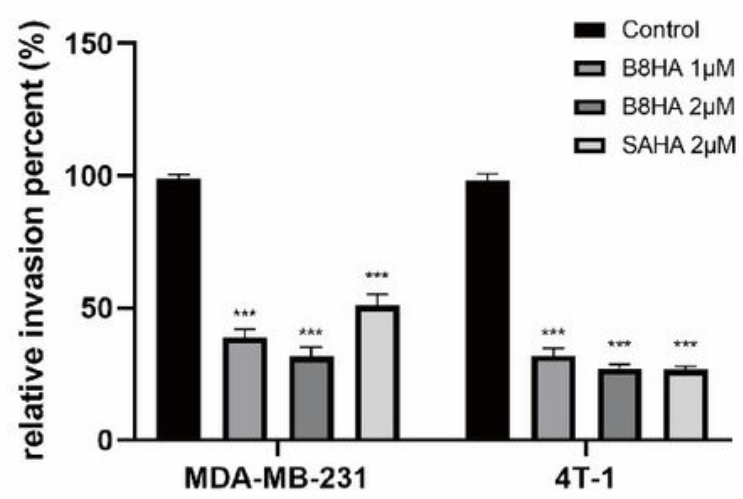

$42 \mathrm{kDa}$

$24 \mathrm{kDa}$

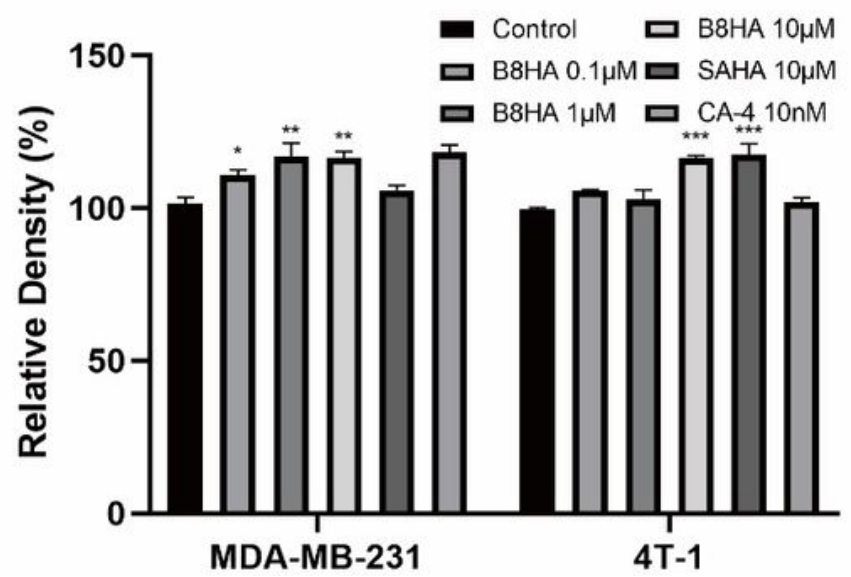

Figure 6

The effect of B8HA on invasion of MDA-MB-231 and 4T1 cells. (A) MDA-MB-231 and 4T1 cells were treated with 1 and $2 \mu \mathrm{M}$ of B8HA and $2 \mu \mathrm{M}$ of SAHA for 24 hours, then the migration ability of the cells 
was detected by wound healing assay and transwell assay. Images were captured under a bright field at 10x magnification. (C) The graph shows the quantitative effect of B8HA. Invasion was quantified by measuring the average number of invading cells. (B, D, E) Detection of MMP-2 and TIMP-2 quantities in cells by WB. ${ }^{*} P<0.05,{ }^{*} P<0.01,{ }^{* \star *} P<0.001$ compared with control. ${ }^{*} P<0.05,{ }^{*} P<0.01,{ }^{* \star *} P<0.001$ compared with control.

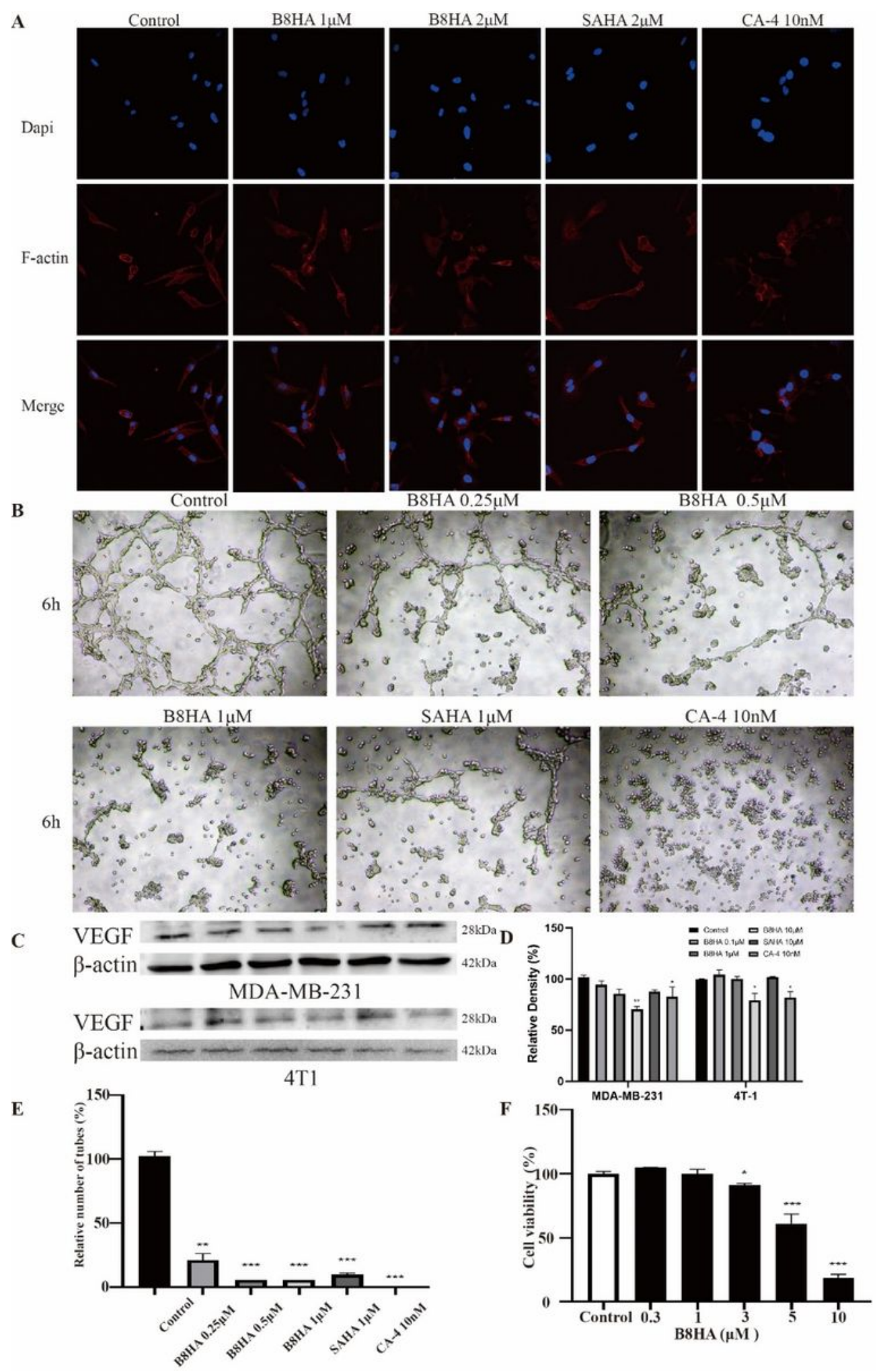

Figure 7 
(A) Immunofluorescence assay to detect the effect of B8HA on HUVEC cytoskeleton. The actin cytoskeleton of HUVEC was stained and analyzed by fluorescence confocal imaging after a 16-hour incubation with B8HA and CA-4. Images were captured at 40x magnification. (scale bar=10 $\mu \mathrm{m})(B, E)$ B8HA inhibits capillary tube formation. The effect of B8HA on capillary tube formation was observed after a 6-hour incubation under an inverted light microscope. Inhibition rates were evaluated after 6 hours incubation. (C, D) Detection of VEGF quantities in cells by WB. (F) Cell viability of HUVEC cells after B8HA treatment. Images were captured under a bright field at 10x magnification. ${ }^{*} p<0.05,{ }^{*} p<0.01$, $\star \star \star \mathrm{P}<0.001$ compared with control. ${ }^{*} \mathrm{P}<0.05,{ }^{\star *} \mathrm{P}<0.01$, ${ }^{\star \star \star} \mathrm{P}<0.001$ compared with control. 
A

oh
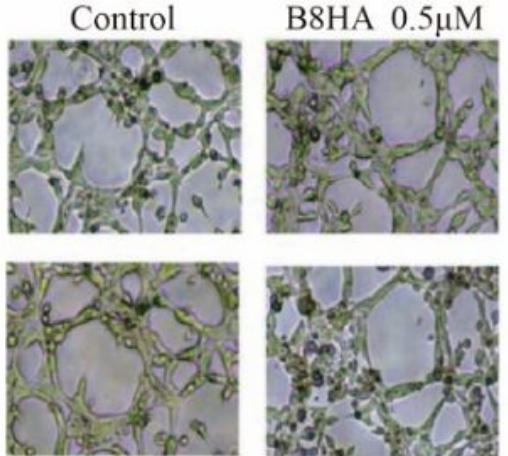

$2 \mathrm{~h}$

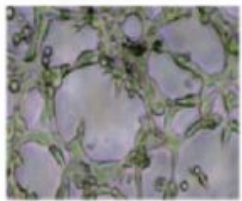

h

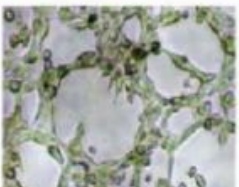

$6 \mathrm{~h}$

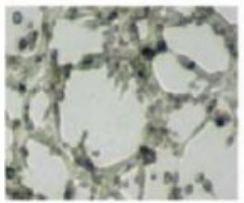

91

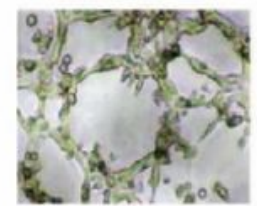

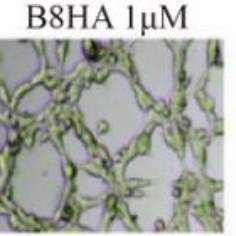
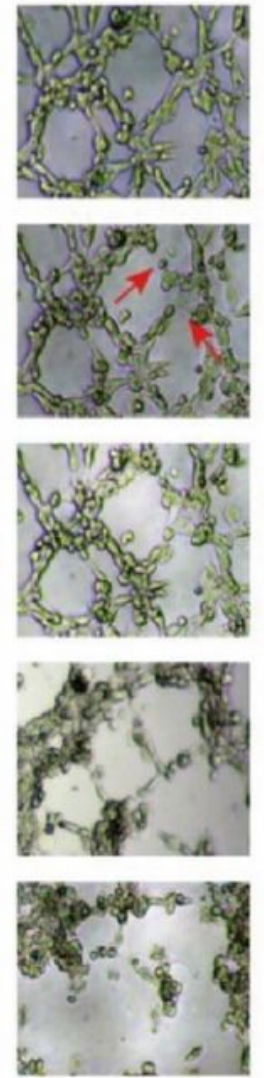
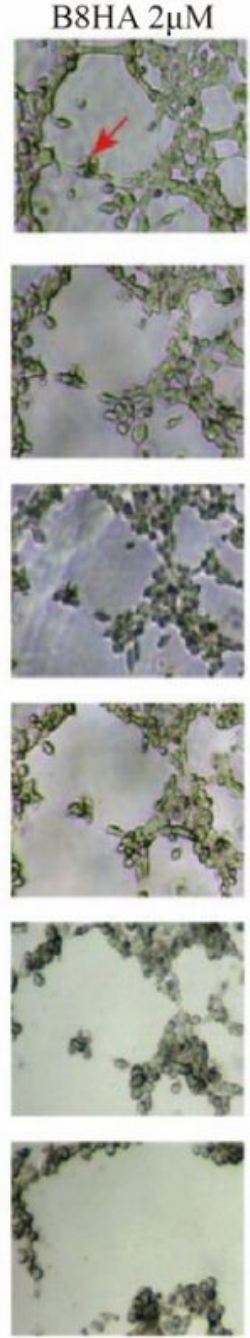

SAHA $1 \mu \mathrm{M}$
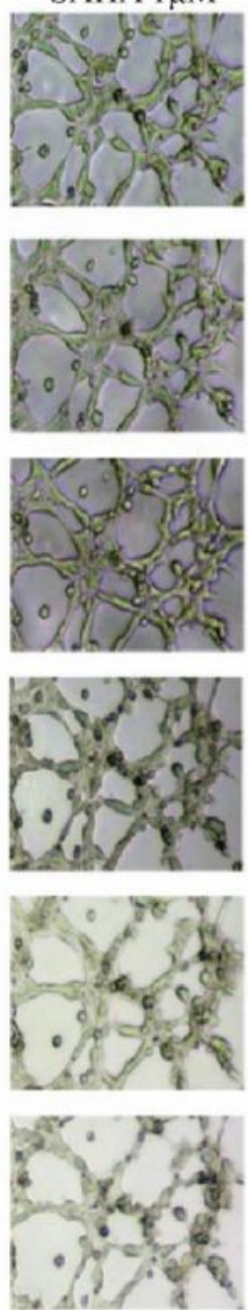

CA-4 10nM
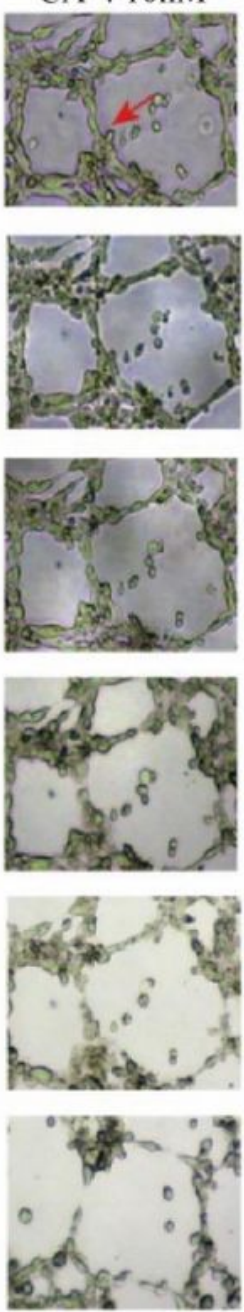

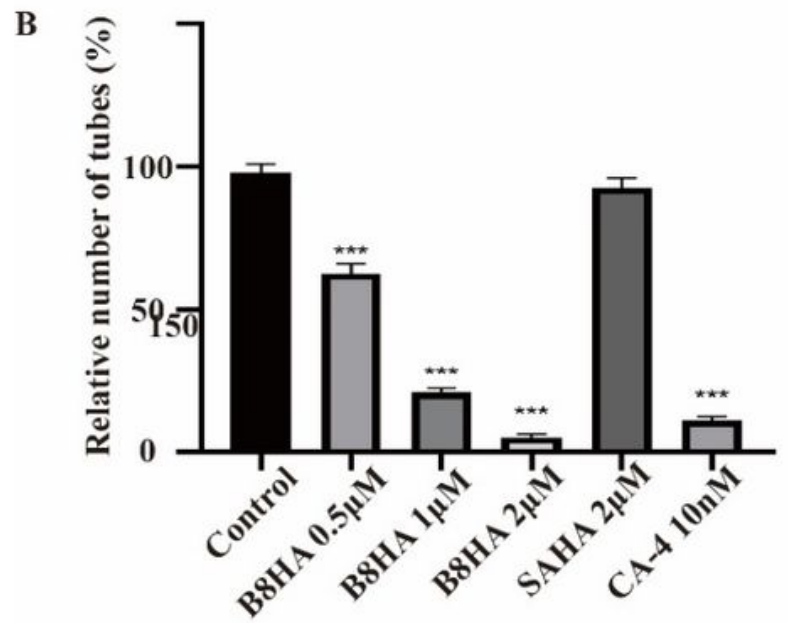

Figure 8

B8HA destabilizes a preestablished vascular network. (A)The effect of B8HA on the disruption of the capillary network was monitored at 0, 1, 2, 3, 6 and 9 hours. (B) Quantitative analysis of the effects of $\mathrm{B} 8 \mathrm{HA}$ on the dimensional and topological parameters of the preformed capillary-like tubule networks after a $9 \mathrm{~h}$ treatment. Images were captured under a bright field at $20 x$ magnification. ${ }^{\star} P<0.05,{ }^{\star} \mathrm{P}<0.01$, $\star \star \star * P<0.001$ compared with control. 

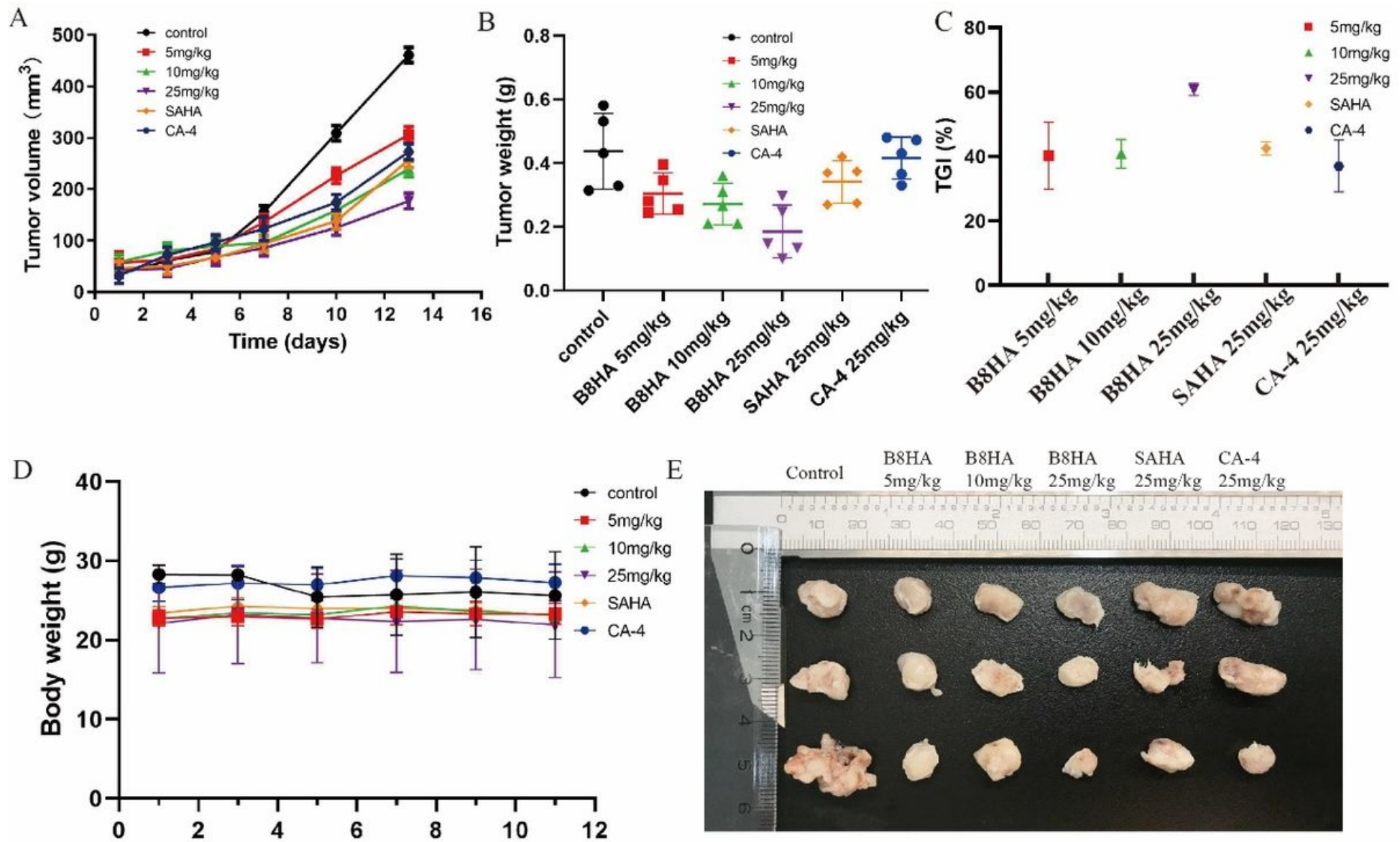

B8HA

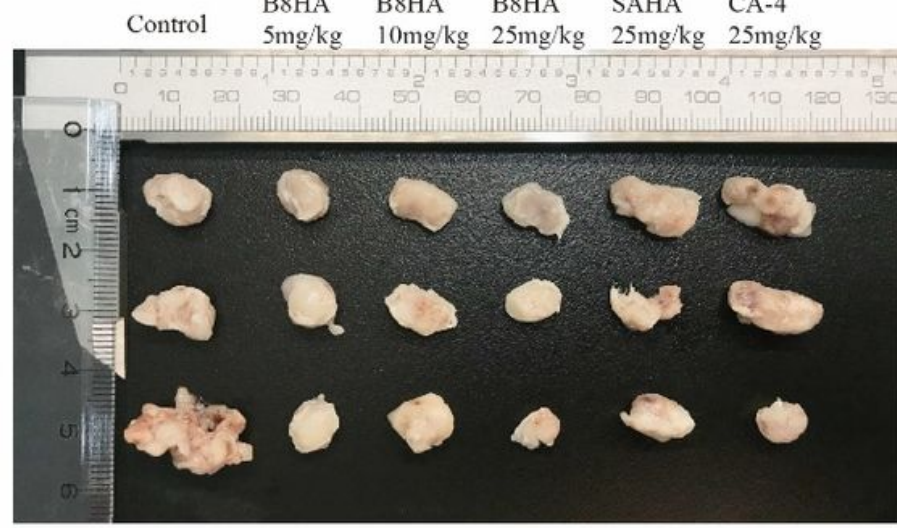

F

Control

B8HA $5 \mathrm{mg} / \mathrm{kg}$

B8HA $10 \mathrm{mg} / \mathrm{kg}$

B $8 \mathrm{HA} 25 \mathrm{mg} / \mathrm{kg}$

SAHA $25 \mathrm{mg} / \mathrm{kg}$

CA-4 25mg/kg
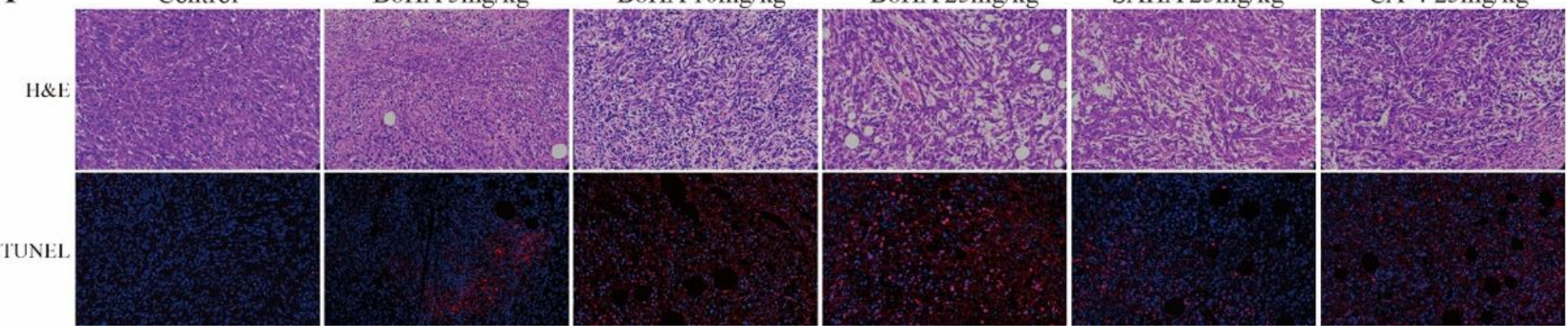

Figure 9

(A)Tumor volume and (B) tumor weight of the 4T1 tumor-bearing Balb/c mice $(n=5)$ after systemic treatment by saline, $25 \mathrm{mg} / \mathrm{kg}$ SAHA, $25 \mathrm{mg} / \mathrm{kg}$ CA-4 and $5,10,25 \mathrm{mg} / \mathrm{kg}$ B8HAC. (C) Isolated tumor after treatment. (D) Body weight of tumor-bearing Balb/c mice. ${ }^{\star} P<0.05$, ${ }^{*} P<0.01,{ }^{*} * * P<0.001$ compared with control. (E) HE staining and TUNEL staining of tumor tissue. Images were captured at 20x magnification. (scale bar=200 $\mu \mathrm{m})$ 
A

Control
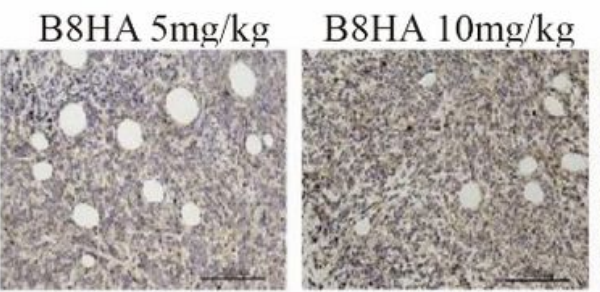

B $8 \mathrm{HA} 25 \mathrm{mg} / \mathrm{kg}$

SAHA $25 \mathrm{mg} / \mathrm{kg}$

$\mathrm{CA}-425 \mathrm{mg} / \mathrm{kg}$
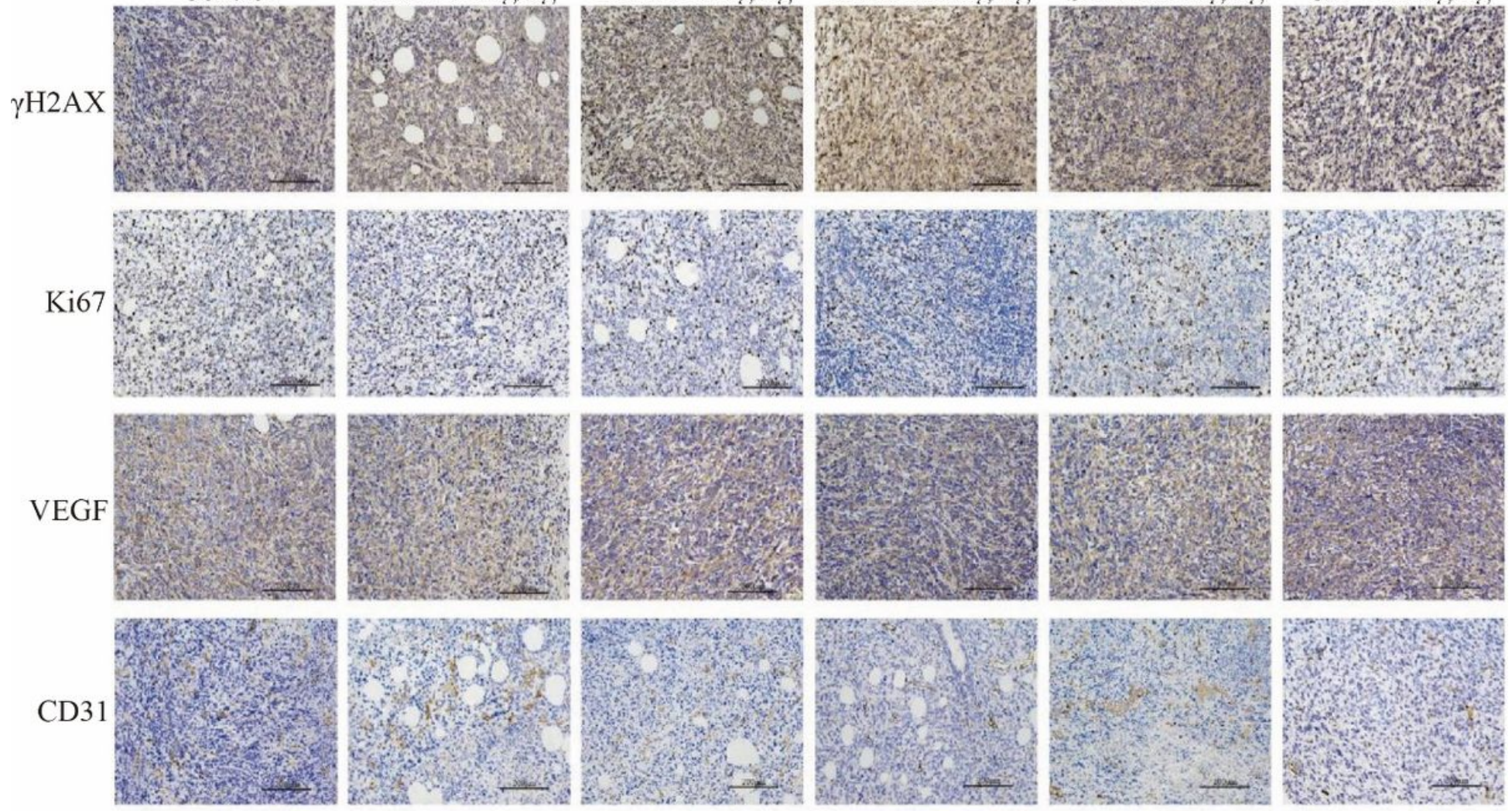

MMP-2
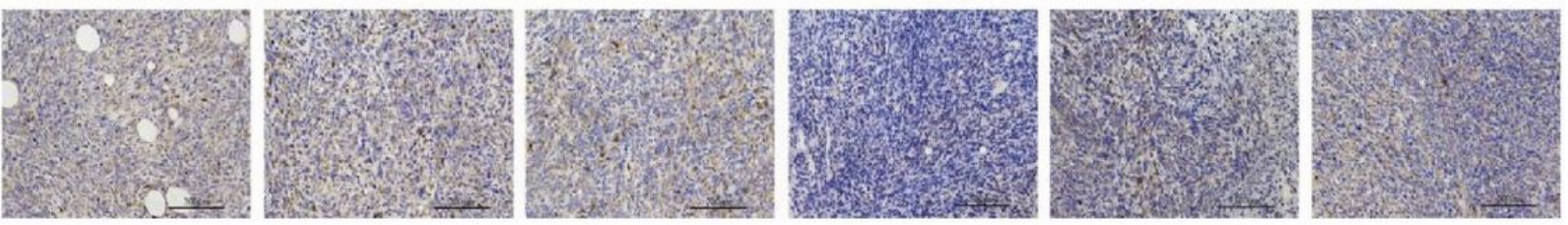

B
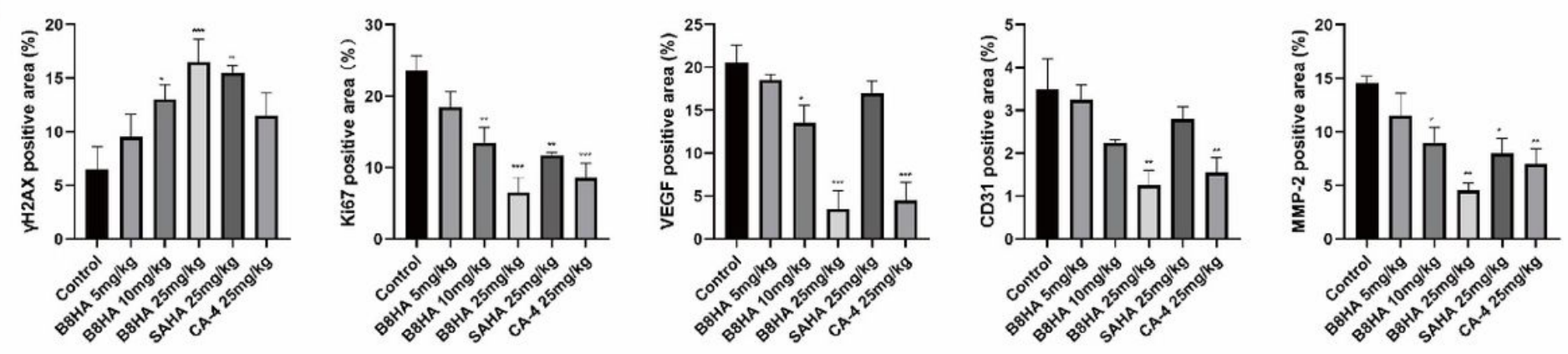

Figure 10

Immunohistochemical staining of tumor tissues after treatment with B8HA. ${ }^{*} P<0.05,{ }^{\star *} P<0.01$, ${ }^{* \star *} \mathrm{P}<0.001$ compared with control. Images were captured under a bright field at 10x magnification. (scale bar=20 $\mu \mathrm{m})$ 


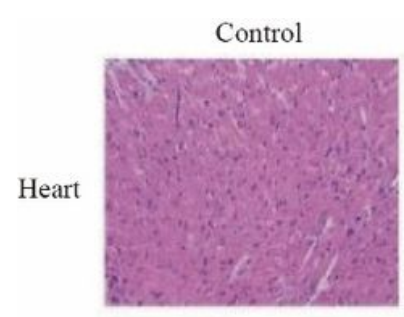

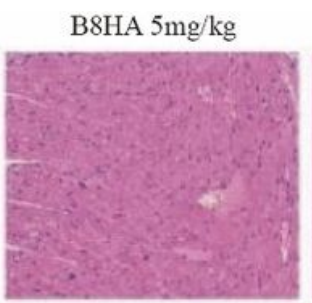
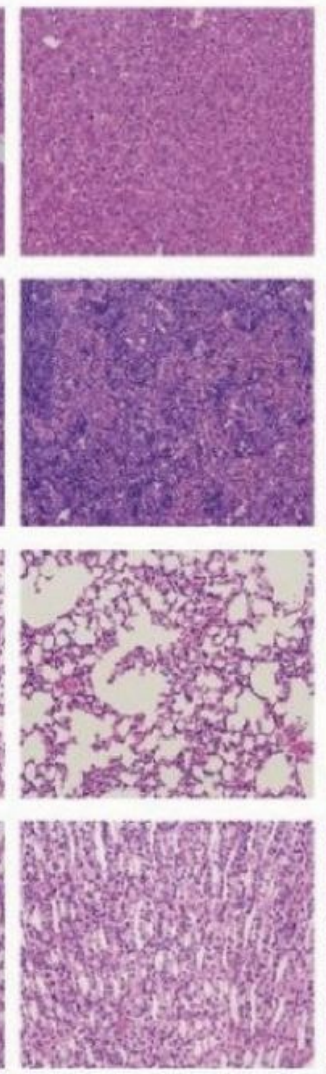

B8HA $10 \mathrm{mg} / \mathrm{kg}$
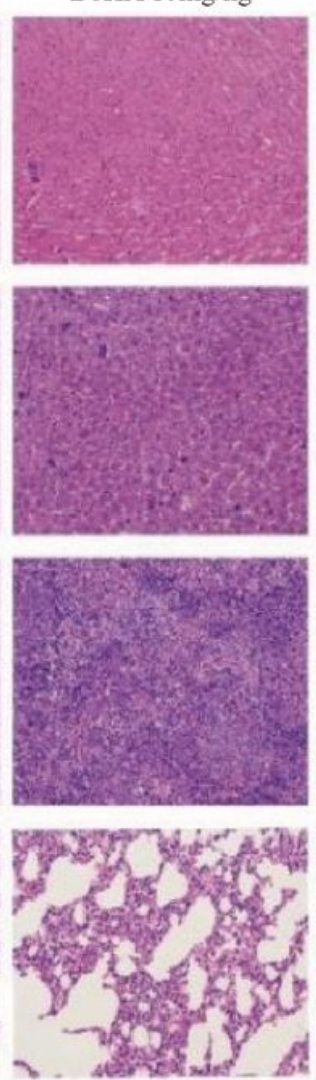

B8HA $25 \mathrm{mg} / \mathrm{kg}$
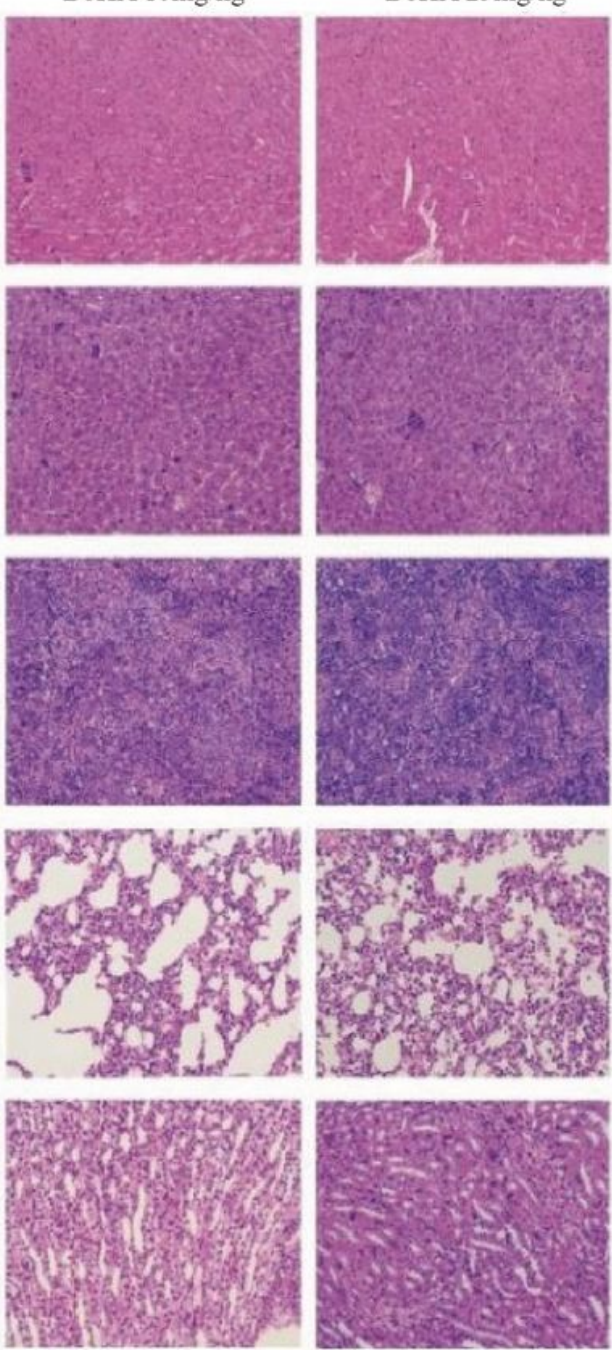

SAHA $25 \mathrm{mg} / \mathrm{kg}$
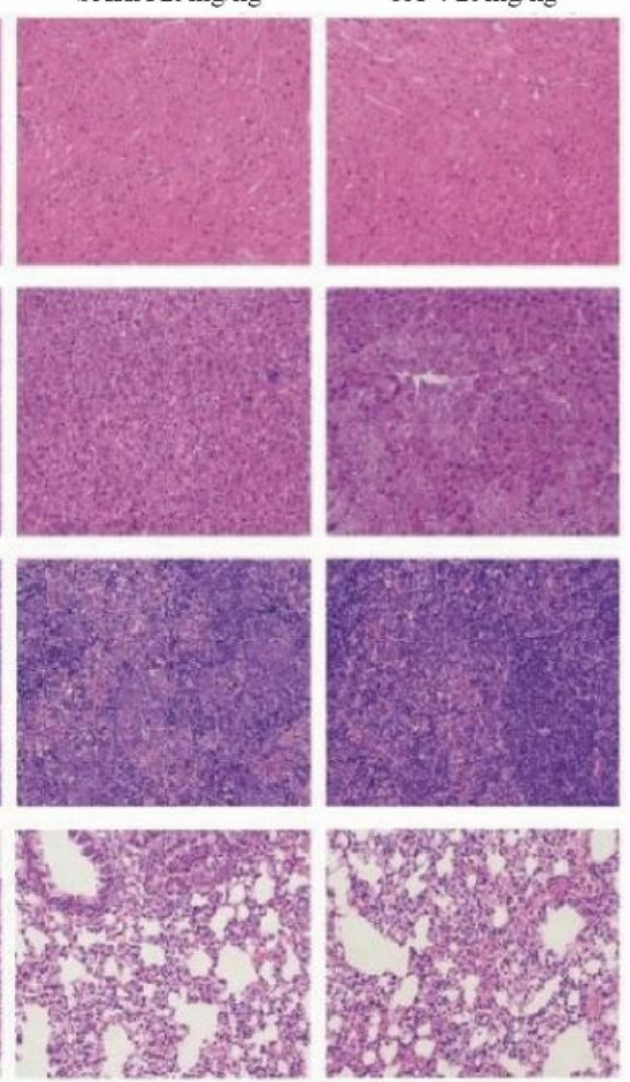

CA-4 $25 \mathrm{mg} / \mathrm{kg}$
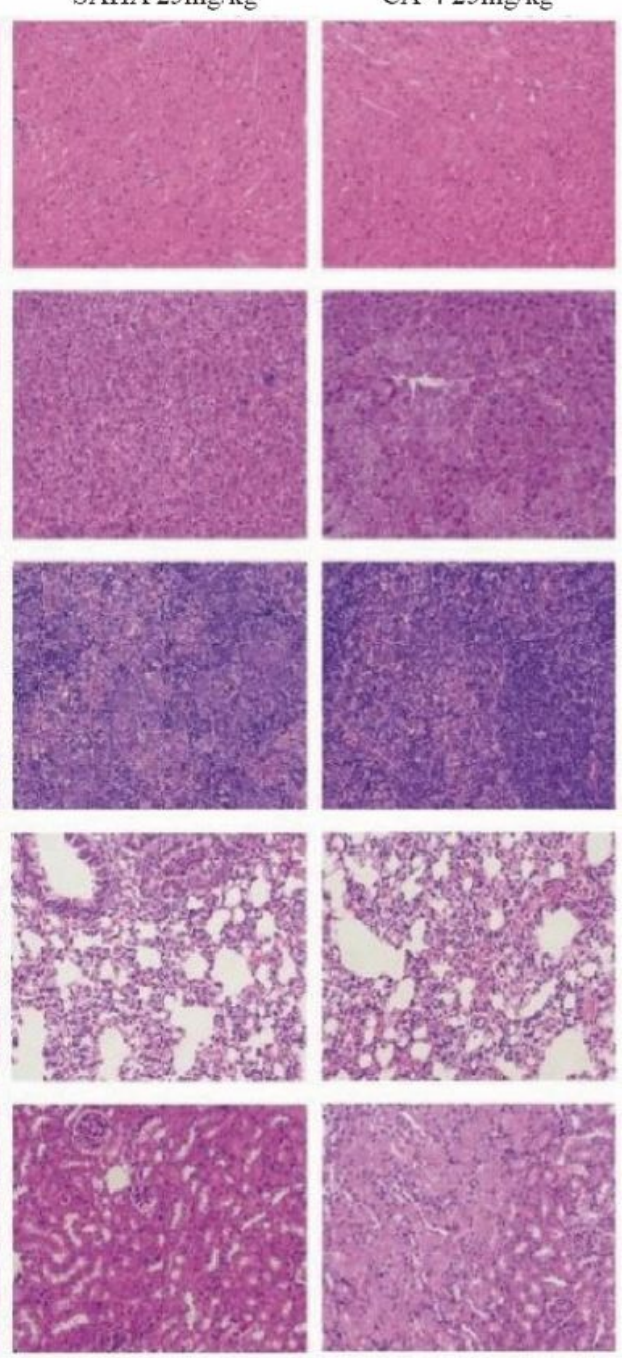

\section{Figure 11}

H\&E staining of mice organs (heart, liver, spleen, lung and kidney) at the end of experiments. Images were captured under a bright field at 10x magnification. 